\title{
A Decline of Observed Daily Peak Wind Gusts with Distinct Seasonality in Australia, 1941-20160
}

\author{
Cesar Azorin-Molina, ${ }^{\mathrm{a}, \mathrm{b}}$ Tim R. McVicar, ${ }^{\mathrm{c}, \mathrm{d}}$ Jose A. Guijarro, ${ }^{\mathrm{e}}$ Blair Trewin, ${ }^{\mathrm{f}}$ Andrew J. Frost, ${ }^{\mathrm{g}}$ \\ Gangfeng Zhang, ${ }^{\text {,h, }, \mathrm{i}}$ Lorenzo Minola, ${ }^{\mathrm{b}}$ SeOK-Woo Son,${ }^{\mathrm{j}}$ Kaiqiang Deng, ${ }^{\mathrm{b}}$ and Deliang Chen ${ }^{\mathrm{b}}$ \\ ${ }^{a}$ Centro de Investigaciones sobre Desertificación, Consejo Superior de Investigaciones Científicas, Moncada, Valencia, Spain \\ ${ }^{\mathrm{b}}$ Department of Earth Sciences-Regional Climate Group, University of Gothenburg, Gothenburg, Sweden \\ ${ }^{\mathrm{c}}$ CSIRO Land and Water, Canberra, Australian Capital Territory, Australia \\ d Australian Research Council Centre of Excellence for Climate Extremes, Australian National University, Canberra, \\ Australian Capital Territory, Australia \\ e State Meteorological Agency (AEMET), Balearic Islands Office, Palma de Mallorca, Spain \\ ${ }^{\mathrm{f}}$ Australian Bureau of Meteorology, Melbourne, Victoria, Australia \\ ${ }^{\mathrm{g}}$ Australian Bureau of Meteorology, Sydney, New South Wales, Australia \\ ${ }^{\mathrm{h}}$ State Key Laboratory of Earth Surface Processes and Resource Ecology, Beijing Normal University, Beijing, China \\ ${ }^{i}$ Academy of Disaster Reduction and Emergency Management, Ministry of Civil Affairs and Ministry of Education, \\ Beijing Normal University, Beijing, China \\ ${ }^{\mathrm{j}}$ School of Earth and Environmental Sciences, Seoul National University, Seoul, South Korea
}

(Manuscript received 25 July 2020, in final form 27 November 2020)

\begin{abstract}
Wind gusts represent one of the main natural hazards due to their increasing socioeconomic and environmental impacts on, for example, human safety, maritime-terrestrial-aviation activities, engineering and insurance applications, and energy production. However, the existing scientific studies focused on observed wind gusts are relatively few compared to those on mean wind speed. In Australia, previous studies found a slowdown of near-surface mean wind speed, termed "stilling," but a lack of knowledge on the multidecadal variability and trends in the magnitude (wind speed maxima) and frequency (exceeding the 90th percentile) of wind gusts exists. A new homogenized daily peak wind gusts (DPWG) dataset containing 548 time series across Australia for 1941-2016 is analyzed to determine long-term trends in wind gusts. Here we show that both the magnitude and frequency of DPWG declined across much of the continent, with a distinct seasonality: negative trends in summer-spring-autumn and weak negative or nontrending (even positive) trends in winter. We demonstrate that ocean-atmosphere oscillations such as the Indian Ocean dipole and the southern annular mode partly modulate decadal-scale variations of DPWG. The long-term declining trend of DPWG is consistent with the "stilling" phenomenon, suggesting that global warming may have reduced Australian wind gusts.
\end{abstract}

\section{Introduction}

The "stilling" phenomenon (Roderick et al. 2007), that is, the observed decline in mean wind speed over terrestrial surfaces in approximately the last 30-50 years (McVicar et al. 2012a), along with the reversal of winds documented since 2013 (Tobin et al. 2014; Zeng et al. 2019), has received much scientific attention in the last two decades. Nevertheless, wind gusts from anemometer observations are still understudied, with very limited research reporting long-term trends and multidecadal variability of wind gusts (Azorin-Molina et al. 2016; Brázdil et al. 2017; Laapas and Venäläinen 2017; Zhang et al. 2020). Moreover, the debate about the causes behind the observed wind speed changes (i.e., stilling vs reversal) remains unclear (Zeng et al. 2018, 2019), and the knowledge about a theoretical connection between a warming climate and the increase in the intensity and frequency of wind extremes is currently weak (Vautard et al. 2019). Understanding the

Supplemental information related to this paper is available at the Journals Online website: https://doi.org/10.1175/JCLI-D-200590.s1.

Corresponding author: Cesar Azorin-Molina, cesar.azorin@uv.es relationship between global warming and wind gusts is crucial to inform the risks posed by human-caused climate change (Walz et al. 2018).

Vose et al. (2014) document how strong surface winds associated with hurricanes, tornadoes, extratropical cyclones, and thunderstorms represent one of the main natural hazards with large socioeconomic and environmental impacts on (i) human safety and casualties, (ii) maritime-terrestrial-aviation activities, (iii) structural design wind actions [Australian/New Zealand Standard (AS/NZS) 1170.2:2011], (iv) homeowners' insurance, and (v) renewable energy production, among others. In Australia, severe winds cause $40 \%$ of the damage to residential buildings, which as a single hazard is higher than either floods, bushfires, or earthquakes, and they caused 2989 deaths between 1824 and 2003 (Wang et al. 2013). The dust storm colloquially called "Red Dawn" (Australian east coast, 22-23 September 2009) impacted soil resources (due to wind erosion), the economy, and human health (breathing related problems).

While scientific consensus of the impact of human-caused climate change on extreme heat and rain is overwhelming (Herring et al. 2016; Bellprat et al. 2019), current understanding of wind gust variability still needs to be significantly improved (Chen et al. 2020). In fact, the existing observational evidence on the signs of trends of wind gusts and storminess under the changing climate are inconclusive, with a slight 
majority of studies reporting declining trends (reviewed by Azorin-Molina et al. 2016). In addition, high-resolution climate model results are not well verified as reliable wind observations are often missing (Nikulin et al. 2010), and they show no retrospective trends (counter to the observations), reducing confidence in the small increase of storminess projected in the future (Vautard et al. 2019).

In Australia, previous studies found a slowdown of nearsurface mean wind speed over the last five decades (McVicar et al. 2008, 2012a), also reporting discrepancies between winds at $2 \mathrm{~m}$ (declines) and at $10 \mathrm{~m}$ (increases) (Troccoli et al. 2012). But there is a lack of knowledge on the multidecadal variability and trends in the magnitude (wind speed maxima) and frequency (90th percentile) of wind gusts (Brown and Dowdy 2019), although a reduction in the frequency of strong winds over southeast Australia during the twentieth century has been inferred from mean sea level pressure data (Alexander et al. 2011). The main reason limiting wind extreme variability research is doubt about the reliability of wind gust observations (AzorinMolina et al. 2014). For instance, a series of artifacts such as (i) station relocations, (ii) anemometer height changes, (iii) instrument malfunctions, (iv) instrument changes, (v) different sampling intervals, and (vi) observing environment changes can impact wind measurements substantially (Azorin-Molina et al. 2018a). Additionally, multidecadal extreme wind observations are often lacking since widespread systematic measurements of wind gusts, which follow the World Meteorological Organization (WMO) recommendation (WMO 1987), mainly commenced in the 1990s (Minola et al. 2020). Therefore, scientists have traditionally been skeptical about analyzing observed wind gust trends.

To ensure the reliability of wind measurements for assessing climate change and variability, climate scientists are increasingly focused on the quality control and homogenization (Venema et al. 2012) of near-surface wind speeds (Wan et al. 2010; Azorin-Molina et al. 2014; Minola et al. 2016; Laapas and Venäläinen 2017), to remove the abovementioned artifacts thus ensuring that observed changes reflect real signals and not inhomogeneities in the data (Conrad and Pollak 1950). For daily peak wind gust series (DPWG), the detection of inhomogeneities is challenging; therefore, only a limited number of approaches have been implemented to date (see Table 1 in Azorin-Molina et al. 2019). For Australia, Azorin-Molina et al. (2019) created the first quality-controlled and homogenized DPWG dataset.

The goal of this paper is to analyze for the first-time longterm trends and multidecadal variability of DPWG across Australia making use of this unique recently developed dataset (Azorin-Molina et al. 2019). This Australian DPWG dataset is the largest one available for any region/continent when simultaneously considering the number of stations and temporal coverage, consisting of 548 series and spanning 76 years (19412016); the second one exists in China, with 778 stations for 1975-2016 (Zhang et al. 2020). Herein our analysis focuses on trends of (i) the magnitude (wind speed maxima) of DPWG and (ii) the frequency of gusts above a given threshold (the 90th percentile) at several temporal scales (i.e., annual, seasonal, and monthly). Seasonal signals are of interest as previous studies pointed out a distinct seasonality of DPWG for other regions (e.g., Azorin-Molina et al. 2016; Zhang et al. 2020). Additionally, this study analyses the impacts of ocean-atmosphere oscillations, vertical atmospheric instability, horizontal pressure gradient, and extratropical cyclones on the DPWG changes. This leads to the secondary goal of determining the leading modes of oceanic-atmospheric variability, and other factors, that influenced past Australian wind gust dynamics. A key aspect of making accurate projections of extreme winds (Walz et al. 2018) lies in gaining new insights into past wind gust variability and its causes (Young and Ribal 2019). Adapting to future wind gusts and associated disaster risks is only possible when reliable projections can be made, as this will be beneficial for decision-makers and a variety of socioeconomic and environmental issues (Vose et al. 2014).

\section{Data and methods}

\section{a. Observed $D P W G$}

Figure 1 shows the location of the 548 stations for which records were supplied by the Australian Bureau of Meteorology (BoM; http://www.bom.gov.au/; last accessed 27 November 2020) and homogenized by Azorin-Molina et al. (2019). The observed DPWG dataset covers the mainland of the Australian continent, the island of Tasmania and several other islands, with a total surface of $7692024 \mathrm{~km}^{2}$. Thus, density is one station per $\sim 14037 \mathrm{~km}^{2}$, which improves the spatial data density of previous studies of mean wind speed in Australia $\left(\sim 48125 \mathrm{~km}^{2}\right.$; McVicar et al. 2008).

DPWG data [in meters per second $\left(\mathrm{m} \mathrm{s}^{-1}\right)$ ] are (i) the highest observed peak gust, defined as the maximum 3-s wind speed (WMO 1987); (ii) measured at $\sim 10 \mathrm{~m}$ above the ground in $24 \mathrm{~h}$ (from 0000 to 0000 local time; i.e., from UTC $+8,+10$, and +11 in Western Australia, eastern Australia, and in summer in some states, respectively); and (iii) recorded by two types of anemometers: Dines pressure tube anemometers (until the 1980s) and Synchrotac 706 rotating cup anemometers in the automatic weather stations (from then onward) (Jakob 2010; Cechet and Sanabria 2012; Azorin-Molina et al. 2019).

In Australia, extreme DPWG are associated with three principal weather phenomena (Dowdy and Catto 2017; Brown and Dowdy 2019): (i) tropical cyclones that affect areas on and near tropical northern Australian coasts; (ii) extratropical cyclones and associated frontal systems that mostly affect southern Australia, particularly Tasmania, and the extratropical east coast; and (iii) local to mesoscale systems such as severe thunderstorms (outflow boundaries/downbursts/gust fronts) and warm-season (October-April; 30-50 per year) and coolseason (May-September; 12 per year) tornadoes (Timbal et al. 2010; Allen and Allen 2016); although they are rarely sampled by the instrumental network. It is worth mentioning that this study analyzes all DPWG observations, which will include the strongest (most damaging) wind gusts and also includes numerous days when winds are light throughout and hence DPWG are low (see section 2d). Along with Fig. 1, Table S1 in the online supplemental material describes the characteristics of each of the 548 homogenized stations used herein. 

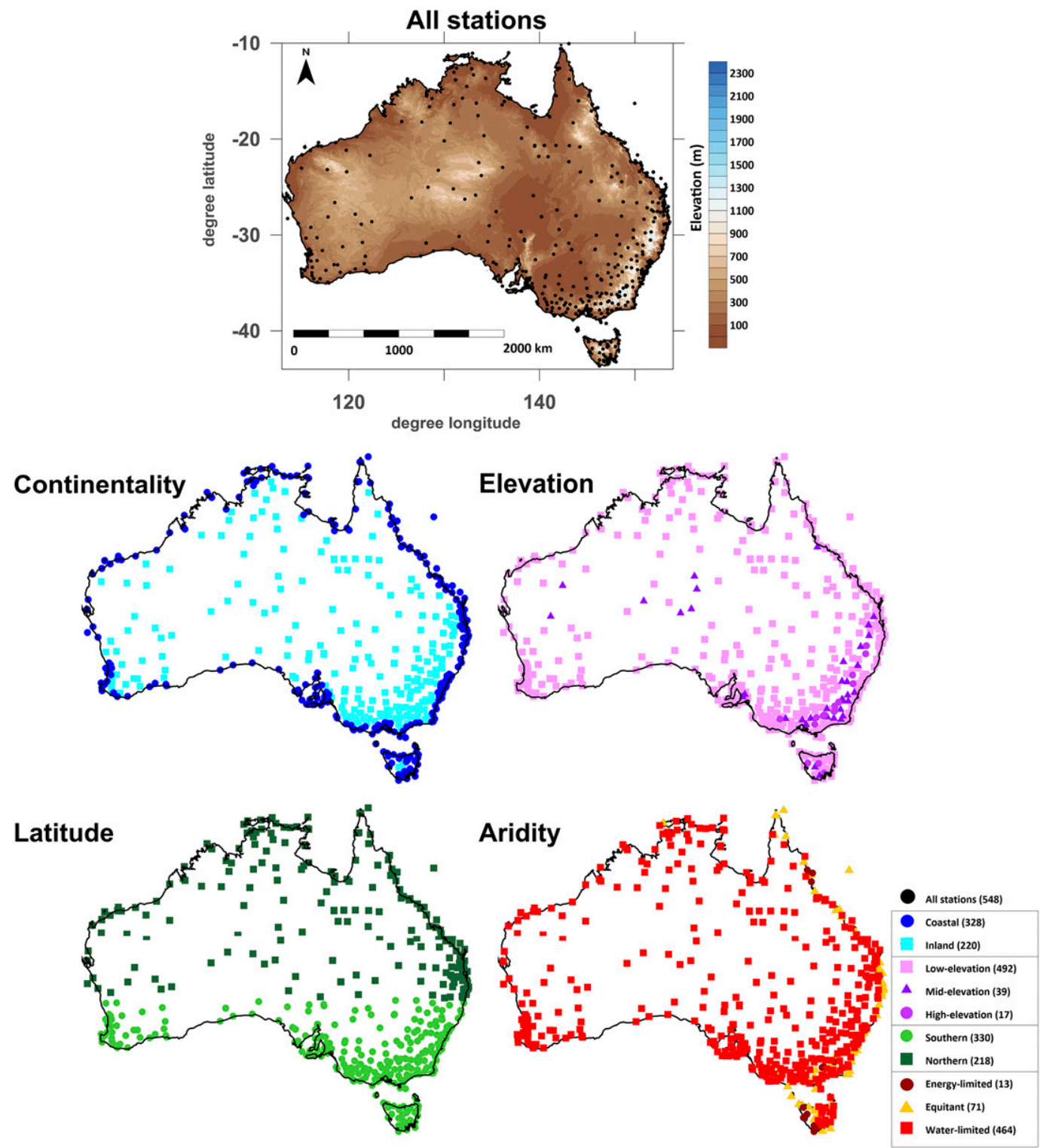

FIG. 1. Land surface elevation of Australia showing location of all 548 stations along with their regionalization into 10 groups according to four criteria: (i) continentality (i.e., coastal, C or inland, I), (ii) elevation [i.e., low-, mid-, or high-elevation (LES, MES, or HES)], (iii) latitude (i.e., southern, S or northern, N), and (iv) aridity [i.e., energylimited, equitant, or water-limited (EL, EQ, or WL)]. The numbers in parentheses denote the number of stations in each group.

\section{b. Homogenization of DPWG}

This study makes use of the first quality-controlled, homogenized, and large (548 series) DPWG dataset across Australia for 1941-2016 created by Azorin-Molina et al. (2019). The approach adopted consisted of breakpoint detection on the monthly scale using R package Climatol, version 3.1. (http://www.climatol.eu/; last accessed 27 November 2020; Guijarro 2018), using the wellestablished relative Alexandersson's standard normal homogeneity test (SNHT; Alexandersson 1986); the splitting of the daily series into homogeneous subperiods; their homogenization without needing the monthly corrections; and the infilling of all missing data with their estimated values. Prior to this homogenization, BoM applied quality controls to remove aberrant data (Aguilar et al. 2003). This strategy represented an advance in the homogenization of DPWG. Full details of this approach are reported in Azorin-Molina et al. (2019), and from this we used the raw and homogenized DPWG series and the list of the corrected breakpoints. Our homogenization protocol and the SNHT test automatically corrected significant shifts due to the underestimation of wind gusts observed by the Synchrotac cup anemometers compared to the older Dines devices (Holmes 
and Ginger 2012). Last, possible outliers $\left(>55.5 \mathrm{~m} \mathrm{~s}^{-1}\right.$ or $\left.>200 \mathrm{~km}^{-1}\right)$ were not automatically removed as for wind gusts there is a high chance of removing real data. However, using BoM records we cross-checked severe wind gusts against a cyclone list, as well as other known gusts such as tornadoes, and validated (or at least considered plausible) all such wind gusts.

The Climatol process infills missing data from neighboring observations, resulting in each of the 548 series being complete. The number of stations with underlying data decreases going back in time (Azorin-Molina et al. 2019), meaning that the resultant series are derived from a progressively sparser observational network in the earliest part of the dataset.

\section{c. Oceanic-atmospheric circulation drivers}

Our secondary goal of determining the leading modes of oceanic-atmospheric variability and other physical drivers followed the approach adopted by Zhang et al. (2020). First, we explored the effect of large-scale oceanic-atmospheric circulation by assessing the annual and seasonal Pearson's correlation coefficient $(r)$ with four well-established teleconnection indices related to decadal variations of oceanic-atmospheric circulation for Australia: (i) El Niño-Southern Oscillation (ENSO), using the Niño-3.4 index (https://www.esrl.noaa.gov/psd/ gcos_wgsp/Timeseries/Nino34/; last accessed 27 November 2020); (ii) Indian Ocean dipole (IOD; https://www.esrl.noaa.gov/psd/ gcos_wgsp/Timeseries/DMI/; last accessed 27 November 2020); (iii) southern annular mode (SAM)/Antarctic Oscillation (https:// climatedataguide.ucar.edu/climate-data/marshall-southern-annularmode-sam-index-station-based; last accessed 27 November 2020); and (iv) Madden-Julian oscillation (MJO; https://www.esrl.noaa. gov/psd/mjo/; last accessed 27 November 2020), here we use the distance from the zero point on the phase diagram where it is situated, which is an indication of the overall level of MJO activity. The relationship of DPWG with the position of the MJO on daily to multiweek time scales is outside the scope of this paper.

Second, physical factors of atmospheric circulation affecting DPWG were initially represented by the large-scale horizontal pressure gradient [Eq. (1)] between high latitudes (HL; i.e., $45^{\circ}-50^{\circ} \mathrm{S}$ ) and low latitudes (LL; i.e., $5^{\circ}-10^{\circ} \mathrm{S}$ ) for the longitudes between $110^{\circ}$ and $155^{\circ} \mathrm{E}$, and regional horizontal pressure gradient force at $850 \mathrm{hPa}$ [Eq. (2)]. An analysis of large-scale horizontal pressure gradient provides enhanced understanding of the possible changes in the strength of horizontal airflow between HL and LL, as Li et al. (2018) and Zhang et al. (2020) recently applied to analyze contributions to wind speed changes under asymmetric warming:

$$
\mathrm{PG}=\left(\sum_{i=1}^{n} \mathrm{PHL}_{i}-\sum_{i=1}^{n} \mathrm{PLL}_{i}\right) / n,
$$

where PG refers to pressure gradient, $i$ indicates the grid number in each latitude band, $n$ refers to the total number of grids in each latitude band, PHL and PLL indicate the air pressure in the HL and LL, respectively.

The regional horizontal pressure gradient force was represented by geostrophic wind (Guo et al. 2011), which demonstrated the horizontal airflow changes at regional scale, and is expressed as

$$
V_{g}=-\frac{1}{f} \frac{\vartheta H}{\vartheta d}
$$

where $V_{g}$ refers to geostrophic wind, $f$ is the Coriolis parameter $\left(\mathrm{s}^{-1}\right), H$ is the geopotential height $\left(\mathrm{m}^{2} \mathrm{~s}^{-2}\right)$, and $\vartheta H$ is the pressure difference associated with the distance $\vartheta d(\mathrm{~m})$.

Further, vertical transport of atmospheric momentum changes was shown as vertical wind shear between 1000 and $850 \mathrm{hPa}$ (Shi et al. 2019) and atmospheric stratification thermodynamic instability ( $A$ index Zhang et al. 2014). Vertical wind shear [Eq. (3)] indicates the vertical air mixing in middle and lower troposphere, and directly affects the wind dynamic momentum downward transport from middle and lower troposphere to near surface, which is shown as

$$
\mathrm{VSW}=\sqrt[2]{\left(U_{850}-U_{1000}\right)^{2}+\left(V_{850}-V_{1000}\right)^{2}}
$$

where VSW refers to vertical wind shear; $U$ and $V$ denote zonal and meridional wind components, respectively. The subscripts denote 850 and $1000 \mathrm{hPa}$.

The $A$ index indicates the strength of the thermodynamic momentum vertically transport in the middle and lower troposphere, which is derived as

$$
\begin{aligned}
A= & \left(T_{850}-T_{500}\right)-\left[\left(T_{850}-\mathrm{Td}_{850}\right)\right. \\
& \left.+\left(T_{700}-\mathrm{Td}_{700}\right)\left(T_{500}-\mathrm{Td}_{500}\right)\right]
\end{aligned}
$$

where $T$ and Td denote air temperature and dewpoint temperature, respectively. The subscripts denote 500, 700, and $850 \mathrm{hPa}$.

The NCEP-NCAR Reanalysis 1 (https://psl.noaa.gov/data/ gridded/data.ncep.reanalysis.pressure.html; last accessed 27 November 2020; Kalnay et al. 1996) was used to compute all these parameters from 1948-2016 and for an area bounded by $10^{\circ}$ and $50^{\circ} \mathrm{S}$ and $110^{\circ}$ and $155^{\circ} \mathrm{E}$.

Additionally, extratropical cyclones (ETCs) are detected and tracked using 6-hourly reanalysis data as in Hoskins and Hodges (2002) and Lee et al. (2020). The JRA-55 data for 1975-2006 are used here (Kobayashi et al. 2015). The ETCs are identified from 850 -hPa relative vorticity field, which is filtered at a T42 spectral resolution. Each local maximum is first detected, and its displacement is tracked by examining its traveling direction and speed. The quasi-stationary thermal lows are discarded by considering only well-defined ETCs with a minimum intensity greater than $1.0 \times 10^{-5} \mathrm{~s}^{-1}$ [or 1 cyclonic vorticity unit (CVU)], a lifetime longer than two days, and a traveled distance greater than $1000 \mathrm{~km}$ (Hoskins and Hodges 2002). Tropical cyclones are also excluded by discarding ETCs originated north of $25^{\circ} \mathrm{S}$; see Lee et al. (2020) for more details. The resulting ETC frequency and intensity are presented in a $2.5^{\circ} \times 2.5^{\circ}$ resolution. The value at a given grid point is set to represent the property within a $555-\mathrm{km}$ radius (Grise et al. 2013; Lee et al. 2020). For instance, one cyclone at a grid point does not indicate one cyclone covering the specific grid point, yet rather represents one cyclone within a $555-\mathrm{km}$ radius from the center of the grid point. This implies that the same cyclone can be simultaneously counted at multiple grid points. 


\section{d. Trend analysis}

Our trend analysis followed the approach adopted by Azorin-Molina et al. (2016) for assessing DPWG trends. Two peak wind gust parameters were calculated for the 548 single DPWG series and for the averaged regional series (i.e., all 548 series across the whole of Australia): (i) the maximum wind speed (magnitude; $\mathrm{m} \mathrm{s}^{-1}$ ) of DPWG and (ii) the number of days (frequency; days) of DPWG events exceeding the 90th percentile (Vose et al. 2014). For the magnitude, we averaged all DPWG data for each station and the regional series at three temporal scales (i.e., annually, seasonally, and monthly). For the 90th percentile, we first determined the highest DPWG decile at each individual station for all months in turn during the whole 1941-2016 study, and then count the number of days in each month above this value. Monthly counts were then aggregated for all seasons and the whole year. Therefore, the magnitude shows all DPWG behavior (i.e., as averages wind gusts for all days), whereas the frequency only represents the extreme winds (i.e., the upper tail of the DPWG distribution). The trend analysis described below was performed at annual, seasonal, and monthly time steps, using austral seasons: winter [June-August (JJA)], spring [September-November (SON)], summer [December-February (DJF)], and autumn [MarchMay (MAM)].

The sign and magnitude of trends in the magnitude and frequency of DPWG across Australia for the 76 years 19412016 were calculated by the slope of an ordinary least squares regression between the series of time (independent variable or $x$ axis) and the wind speed maxima or the number of days in the highest decile (dependent variable or $y$ axis). Running trends for window lengths from 20 (i.e., 1941-60) to 76 years (i.e., 1941-2016) are also computed. The magnitude of DPWG trends is reported decadally (i.e., units are $\mathrm{m} \mathrm{s}^{-1}$ decade $^{-1}$ ) and the frequency of DPWG, along with a 15 years Gaussian lowpass filter used to analyze the multidecadal variability, are reported in units of days per decade (days decade ${ }^{-1}$ ). Moreover, a three-step statistical protocol (Azorin-Molina et al. 2016) was applied to quantify the statistical significance of the magnitude and frequency of DPWG changes: (i) 1-month lag autocorrelation coefficient (von Storch 1995), as significant autocorrelations increase the probability of detecting significant trends; (ii) nonparametric correlation coefficient of Mann-Kendall's tau-b (Kendall and Gibbons 1990) to report the statistical significance of the linear trends in three $p$ level categories: significant at $p<0.05$, significant at $p<0.10$ and not significant at $p<0.10$, as many other previous studies reported (e.g., Azorin-Molina et al. 2014; Minola et al. 2016); and (iii) field significance to detect whether the significant trends have occurred by chance (Livezey and Chen 1983; Wilks 2006; Dadaser-Celik and Cengiz 2014). Last, to compare with the results of McVicar et al. (2008), who first analyzed trends in mean wind speed across Australia for 1975-2006, we also repeated the trend analysis for that subperiod.

\section{e. Regionalization of stations}

Because wind variability is strongly influenced by terrain features (Jiménez and Dudhia 2012), here we define a classification to group stations affected by similar physical processes to explore if trends of DPWG differ among regions. For example, by plotting mean DPWG for each station during 1941-2016 versus the station distance to the sea and its elevation (Fig. S1), stations cluster into three groups: (i) coastal stations, where land-sea air temperature and roughness differences are a major influence on wind variability (e.g., sea breezes; Achberger et al. 2006); (ii) inland stations, where winds are strongly affected by Earth-atmosphere interaction by turbulent transport, and wind gusts are most often the result of deep convection (e.g., downbursts); and (iii) high-elevation stations, which are affected by both strong large-scale synoptic winds and local circulations driven by complex topography (Rotach et al. 2015). Therefore, following previous studies and as seen in Fig. S1, we define four different categorizations of stations: (i) continentality, with coastal ( $\mathrm{C} ; \leq 45 \mathrm{~km}$ to the coastline) and inland ( $\mathrm{I} ;>45 \mathrm{~km}$ to the coastline) stations (McVicar et al. 2008); (ii) elevation, distinguishing between low-elevation stations $<500 \mathrm{~m}$ MSL (LES), midelevation 500$1000 \mathrm{~m}$ MSL (MES), and high elevation > $1000 \mathrm{~m}$ MSL (HES) (Zhang et al. 2020); (iii) latitude, with southern (S; $<30^{\circ} \mathrm{S}$ ) and northern $\left(\mathrm{N} ;>30^{\circ} \mathrm{S}\right)$ stations, as the approximate northern limit of zonal mean westerlies in winter over the bulk of the Australian continent; and (iv) the aridity index (AI; calculated as long-term annual average potential evapotranspiration divided by long-term annual average precipitation), classifying stations as (i) energy-limited (EL; where AI < 0.76), (ii) equitant (EQ; $0.76<\mathrm{AI}<1.35$ ), and (iii) water-limited (WL; where AI > 1.35); see McVicar et al. (2012b). Figure 1 shows the spatial distribution of stations regionalized into these categories according to these four criteria.

\section{Results}

\section{a. DPWG climatology}

Figure 2 displays the spatial climatology of DPWG across Australia for 1941-2016, using four statistical parameters: mean, standard deviation, and maximum and minimum values. Figure 3 shows box-and-whisker plots of the intra-annual variation of DPWG (see Fig. S2 for monthly plots). Overall, DPWG show annual mean values of $11.4 \mathrm{~m} \mathrm{~s}^{-1}$, with most of the series in the $10-12(49.8 \%)$ and $12-14(24.5 \%) \mathrm{m} \mathrm{s}^{-1}$ ranges. The highest and lowest mean annual DPWG values are recorded in the southern (Tasmania, $20.7 \mathrm{~m} \mathrm{~s}^{-1}$ ) and northern/ eastern $\left(7.1 \mathrm{~m} \mathrm{~s}^{-1}\right)$ regions, respectively; showing noticeable latitudinal and longitudinal gradients in mean annual DPWG. In general, three principal regions are identified according to mean annual DPWG: (i) Tasmania/southeastern coast of Australia, where mean DPWG are $>14 \mathrm{~m} \mathrm{~s}^{-1}$ due to the high frequency of strong winds associated with extratropical cyclones, which are most frequent over the southernmost parts of Australia (Jones and Simmonds 1993); (ii) some other coastal areas where mean DPWG ranges between 12 and $14 \mathrm{~m} \mathrm{~s}^{-1}$ as driven by differences in air pressure originated by the differing heat capacities of ocean and land surfaces (Jones and Simmonds 1993); and (iii) inland areas and much of southeastern and northern Australia with mean DPWG ranging 


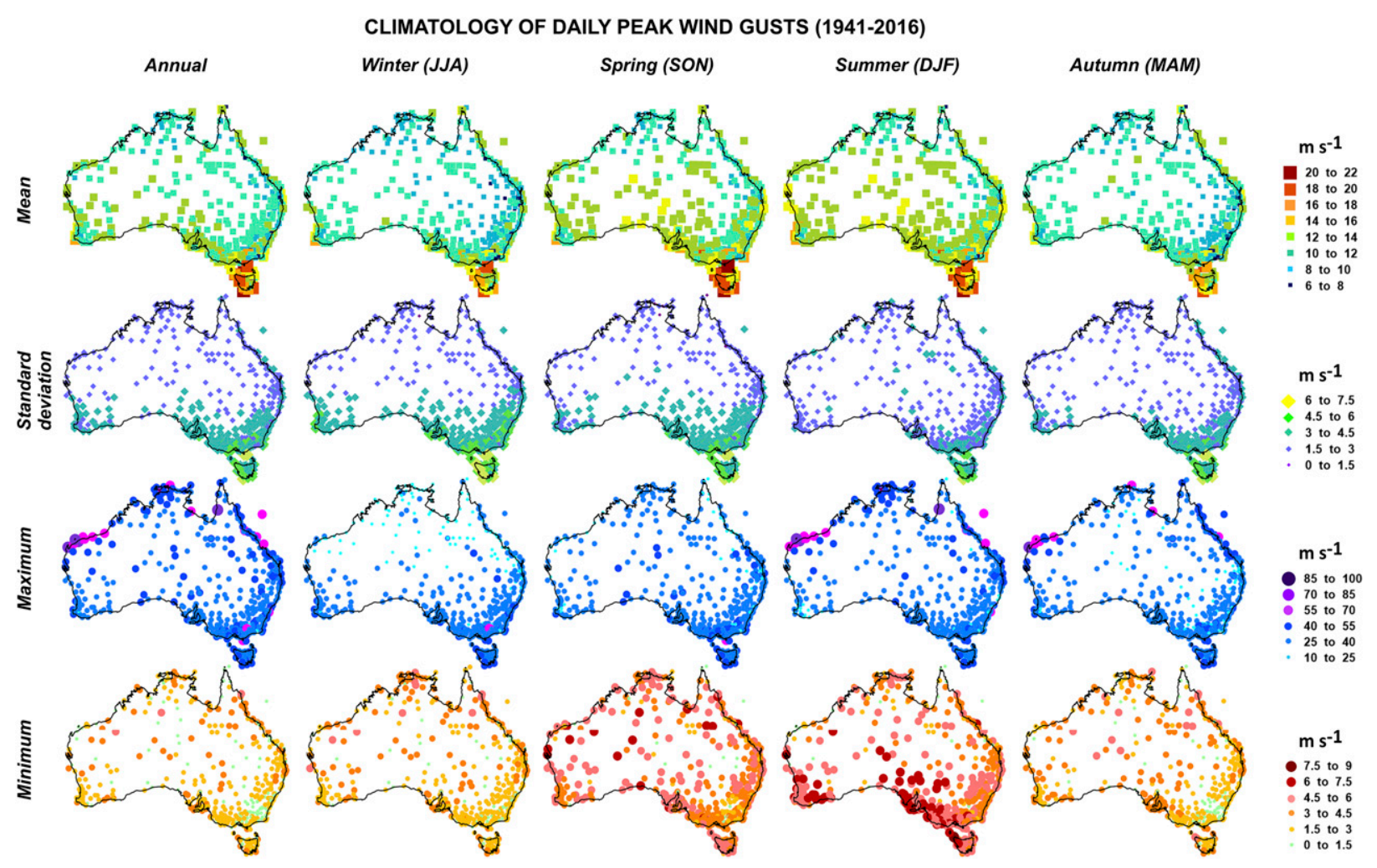

FIG. 2. Annual and seasonal spatial distributions of the mean, standard deviation, and maximum and minimum ( $\mathrm{m} \mathrm{s}^{-1}$ ) of DPWG for all 548 homogenized stations for 1941-2016.

between 10 and $12 \mathrm{~m} \mathrm{~s}^{-1}$ due to the dominance of atmospheric stability and a relatively low frequency of cyclones (Jones and Simmonds 1993). This spatial pattern is similar between seasons at the continental scale, with spring $\left(12.2 \mathrm{~m} \mathrm{~s}^{-1}\right)$ and summer $\left(12.3 \mathrm{~m} \mathrm{~s}^{-1}\right)$ showing highest values of mean DPWG, and winter $\left(10.7 \mathrm{~m} \mathrm{~s}^{-1}\right)$ and autumn $\left(10.6 \mathrm{~m} \mathrm{~s}^{-1}\right)$ the lowest.

The geographic patterns of mean DPWG maps differ with those of extreme gusts. For instance, it is noticeable that the areas with the extreme maximum DPWG (generally those affected by tropical cyclones), are not the ones with the highest mean DPWG. Tropical cyclones are relatively infrequent events at any specific location, with an average of about 11 cyclones per year in the Australian region, of which only $40 \%$ make landfall (Chand et al. 2019) and have a relatively small spatial scale (relative to extratropical cyclones) with extreme winds rarely exceeding a path more than $200-300 \mathrm{~km}$ wide. During 1941-2016, the BoM observed 35 events when wind gusts exceeded $55.5 \mathrm{~m} \mathrm{~s}^{-1}$ (i.e., $200 \mathrm{~km} \mathrm{~h}^{-1}$ ), with the highest observed gust of $74.1 \mathrm{~m} \mathrm{~s}^{-1}\left(266.8 \mathrm{~km} \mathrm{~h}^{-1}\right.$; observed, that is, not infilled or adjusted in the homogenization) at the Learmonth airport (near the town of Exmouth on the northwest coast of Western Australia) on 22 March 1999. Almost all of these 35 events were associated with tropical cyclones. The most extreme DPWG values occur on northern coastlines exposed to tropical cyclones, although with considerable variation from site to site, with a secondary maximum in Tasmania and coastal southeastern Australia where extratropical cyclones have a strong influence, especially in winter and spring. The lowest values (as low as $21.3 \mathrm{~m} \mathrm{~s}^{-1}$ ) of the maximum DPWG mostly occur in inland areas, particularly in winter and spring. The lowest DPWG values occur in autumn and winter in southern Australia.

Last, the standard deviation and interquartile range (25th and 75th percentiles) of DPWG shows a similar pattern both annually and seasonally, with a strong gradient between the southern (also coastal) region where large deviation values (up to $7.3 \mathrm{~m} \mathrm{~s}^{-1}$ in winter) dominate and the center and northern regions where very low deviation values (down to $1.3 \mathrm{~m} \mathrm{~s}^{-1}$ in spring) exist. These standard deviations reveal that in the southern and coastal regions (particularly in winter) the magnitude of DPWG differs from one day to the next due to the influence of changing synoptic situations (e.g., extratropical cyclones vs high pressure systems), while in the central and northern regions for much of the year (and in summer and autumn in the south) similar weather patterns associated with the subtropical high pressure ridge, and easterly flow on its northern side, occur on most days.

\section{b. Long-term spatiotemporal trends in the magnitude of $D P W G$}

Overall, the magnitude of DPWG declined significantly for the annual all-Australian series over $1941-2016\left(-0.067 \mathrm{~m} \mathrm{~s}^{-1}\right.$ decade $\left.^{-1}, p<0.05\right)$. It also declined in each of the regional series (Table 1). This weakening in the magnitude of DPWG 


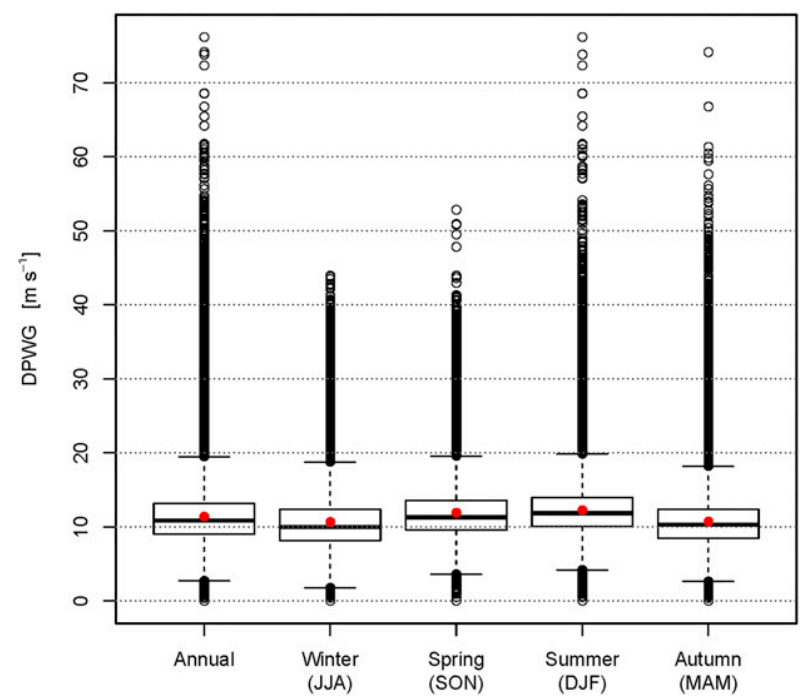

FIG. 3. Annual and seasonal box-and-whisker plots of DPWG for all 548 homogenized series for 1941-2016. The mean (red dot), the median (thick black line), the 25 th and 75 th percentile range (boxes), the 10th and 90th percentiles (whiskers), and the outliers (dots) are represented, respectively. Monthly box-and-whisker plots are shown in Fig. S2.

was also observed for the averaged regional series for all seasons, being widespread and statistically significant $(p<0.05)$ in spring $\left(-0.096 \mathrm{~m} \mathrm{~s}^{-1}\right.$ decade $\left.^{-1}\right)$, summer $\left(-0.101 \mathrm{~m} \mathrm{~s}^{-1}\right.$ decade $\left.^{-1}\right)$, and autumn $\left(-0.048 \mathrm{~m} \mathrm{~s}^{-1}\right.$ decade $\left.^{-1}\right)$. However, in winter $\left(-0.024 \mathrm{~m} \mathrm{~s}^{-1}\right.$ decade $\left.^{-1}, p>0.10\right)$ nonsignificant trends dominated for all regions, with weak increases in the HES and EL classes. For 1975-2006 (Table S2), we mostly found negative, but nonsignificant trends, with a stronger decline in summer $\left(-0.121 \mathrm{~m} \mathrm{~s}^{-1}\right.$ decade $\left.^{-1}, p<0.05\right)$ and a weak increase of DPWG in winter $\left(+0.054 \mathrm{~m} \mathrm{~s}^{-1}\right.$ decade $\left.^{-1}, p>0.10\right)$.

Figure 4 shows the annual and seasonal multidecadal variability in the magnitude of DPWG across all stations for 19412016 (see Fig. S3 for monthly plots). Annually, the Gaussian low-pass filter displays three well-defined phases: (i) an abrupt increase from 1941 until $1953\left(12.0 \mathrm{~m} \mathrm{~s}^{-1}\right)$; followed by (ii) a sudden decline since the mid-1950s until $1974\left(11.2 \mathrm{~m} \mathrm{~s}^{-1}\right)$; and (iii) a stabilization or slight slowdown in the magnitude of DPWG until 2016, with the lowest mean DPWG recorded in 2010-11 (11.0 $\left.\mathrm{m} \mathrm{s}^{-1}\right)$. These three phases and the high values observed in the magnitude of DPWG around the mid-1950s were also detected seasonally, particularly in spring, summer, and autumn, except for winter that experienced a weak recovery in the last 3-4 decades. Moreover, the running trends of the magnitude of DPWG shown in Fig. 5 highlight the dominance of significant negative trends, except for weak but not significant positive trends in the 1960s and 2000s for time periods $<30$ years.

Table 2 reports the monthly DPWG trends for all stations and the regional series (Table S3 reports monthly trends for 1975-2006). While negative trends dominate throughout the year, there is a noticeable monthly cycle in the magnitude and significance of the negative trends. For instance, significant $(p<0.05)$ and negative trends dominated from September until April, with the largest absolute negative trends in November $\left(-0.151 \mathrm{~m} \mathrm{~s}^{-1}\right.$ decade $\left.^{-1}\right)$ and December $\left(-0.121 \mathrm{~m} \mathrm{~s}^{-1}\right.$ decade $\left.^{-1}\right)$. On the contrary, nonsignificant $(p>0.10)$ negative trends were reported from May until August, with the weakest negative trend in June $\left(-0.006 \mathrm{~m} \mathrm{~s}^{-1}\right.$ decade $\left.^{-1}\right)$. The same monthly cycle was seen in all regions, with the exception of HES, EL, and EQ where positive but nonsignificant trends are reported during the winter months. In fact, a positive and significant trend in the magnitude of DPWG is found in June for HES $\left(+0.126 \mathrm{~m} \mathrm{~s}^{-1}\right.$ decade $\left.^{-1} ; p<0.05\right)$. Regionally, both annually and seasonally (Table 1 ), and monthly (Table 2), it is noteworthy that changes in the magnitude of DPWG trends are roughly greater in the C class than in the I class; in the HES than in the LES and the MES classes; in the S rather than the $\mathrm{N}$ of the country; and in the EL areas.

The annual and seasonal spatial distribution of the 548 station-based trends for 1941-2016 (i.e., sign, magnitude of change, and statistical significance) are shown in Fig. 6; and summarized in Table 3. Annually (Fig. 6a), 99.6\% of stations showed negative trends $(81.7 \%$ being significant at $p<0.05)$. This widespread weakening in the magnitude of DPWG was largest and most significant in the southern (e.g., Tasmania) and southwestern parts of Australia, with a noticeable latitudinal gradient as this slowdown was weakest and nonsignificant toward the north and northwest. Seasonally, spring (95.4\%; Fig. 6c), summer (91.6\%; Fig. 6d), and autumn (85.8\%; Fig. 6e) had similar patterns, with some exceptions such as the large and significant declines in the north and eastern coast in spring and summer; and the upward trends in the magnitude of DPWG detected in the east in autumn. Winter, in contrast, showed a different spatial pattern with $38.5 \%$ increasing (29.9\% being significant at $p<0.05$; Fig. 6b), mainly in northern Australia and some stations in the southeast. Monthly

TABLE 1. Annual and seasonal trends in the mean magnitude of DPWG $\left(\mathrm{m} \mathrm{s}^{-1} \mathrm{decade}^{-1}\right)$ for all 548 stations and the regional series for 1941-2016. The columns to the right of "All" denote classes defined by four criteria and their locations and the number of stations in each are provided on Fig. 1. Statistically significant trends at $p<0.10$ are in bold and $p<0.05$ are bold and in parentheses.

\begin{tabular}{|c|c|c|c|c|c|c|c|c|c|c|c|}
\hline & All & $\mathrm{C}$ & I & LES & MES & HES & S & $\mathrm{N}$ & EL & EQ & WL \\
\hline Annual & $(-0.067)$ & $(-0.071)$ & $(-0.063)$ & $(-0.067)$ & $(-0.069)$ & $(-0.093)$ & $(-0.077)$ & $(-0.057)$ & $(-0.095)$ & $(-0.076)$ & $(-0.066)$ \\
\hline JJA & -0.024 & -0.013 & -0.039 & -0.026 & -0.023 & +0.066 & -0.029 & -0.018 & +0.050 & +0.000 & -0.028 \\
\hline SON & $(-0.096)$ & $(-0.108)$ & $(-0.079)$ & $(-0.096)$ & $(-0.088)$ & $(-0.135)$ & $(-0.103)$ & $(-0.089)$ & $(-0.156)$ & $(-0.117)$ & $(-0.092)$ \\
\hline DJF & $(-0.101)$ & $(-0.116)$ & $(-0.079)$ & $(-0.097)$ & $(-0.104)$ & $(-0.257)$ & $(-0.114)$ & $(-0.087)$ & $(-0.250)$ & $(-0.149)$ & $(-0.092)$ \\
\hline MAM & $(-0.048)$ & $(-0.045)$ & $(-0.053)$ & $(-0.048)$ & $(-0.059)$ & -0.047 & $(-0.061)$ & $(-0.035)$ & -0.025 & -0.038 & $(-0.050)$ \\
\hline
\end{tabular}




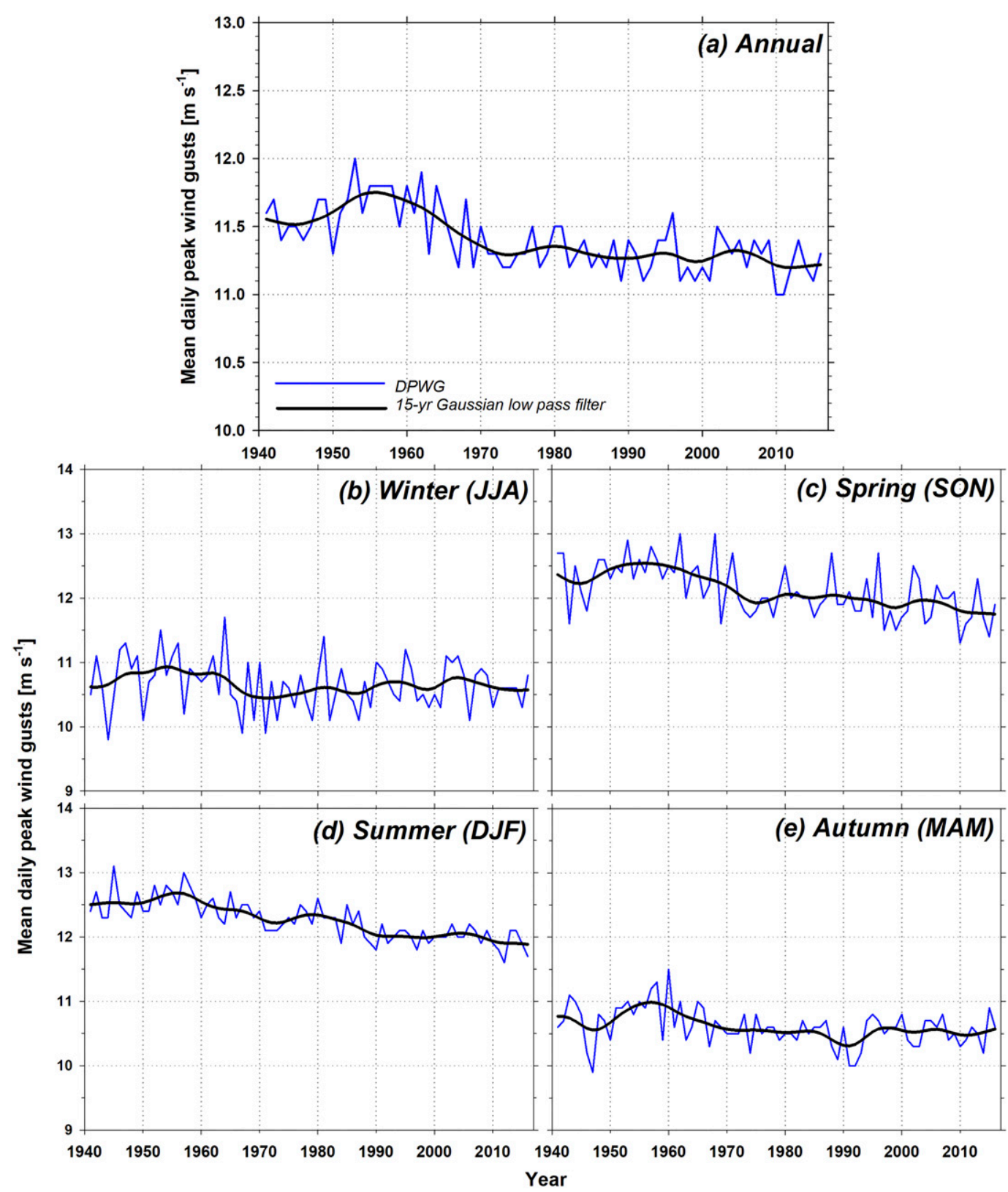

FIG. 4. Annual and seasonal mean wind speed of DPWG in Australia for 1941-2016. The 15 years Gaussian lowpass filter is also shown with a black solid line. Monthly plots are shown in Fig. S3.

plots shown in Fig. 7 (summarized in Table S4a) display a distinct intra-annual pattern, with a gradual transition from a large number of stations showing negative and significant trends in January $(87.0 \% ; 64.4 \%$ being significant at $p<0.05)$ to a minimum in June $(54.6 \% ; 14.4 \%$ being significant at $p<$ $0.05)$, and again the largest number of significant declines toward the end of the year $(94.5 \% ; 72.8 \%$ at $p<0.05$ in November). The increases in the magnitude of DPWG for 1941-2016 occurred from May till August, and mostly affected northern Australia. Figure S4 and Table S5a (annual and seasonal) and Fig. S5 and Table S6a (monthly) for 1975-2006 support this distinct seasonal cycle in the trends of the magnitude of DPWG, even for this shorter subperiod.

\section{c. Long-term spatiotemporal trends in the frequency of $D P W G$}

Table 4 shows that trends in the frequency of DPWG have similarities to the reported trends in their magnitude. Annually, the number of days with DPWG events exceeding the 90 th percentile declined at a rate of -5.360 days decade ${ }^{-1}$ $(p<0.05)$ for all stations during 1941-2016. This means fewer events in the 90th percentile occurred toward to the end of the 


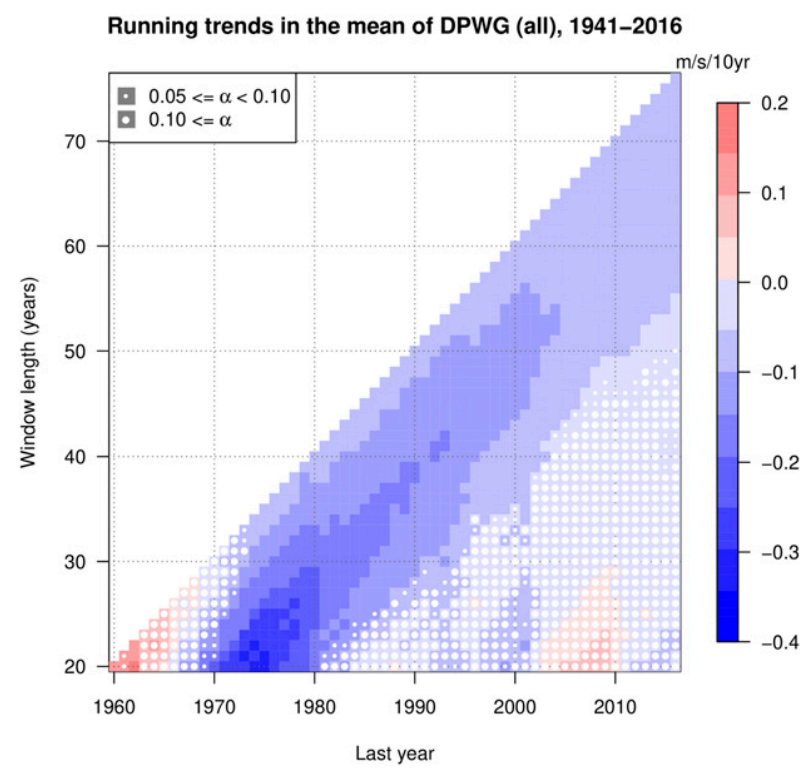

FIG. 5. Running trends of mean wind speed of DPWG in Australia for 1941-2016. White dots partially mask the nonsignificant (i.e., $p>0.10$ ) trends.

series when compared to the start, consistent with the significant decline in the annual magnitude of DPWG as shown above. Seasonally, we found the same trend behavior as for the magnitude, with the strongest and significant $(p<0.05)$ declines in the frequency of 90th percentile wind gusts in spring $\left(-1.246\right.$ days decade $\left.^{-1}\right)$, summer $\left(-1.678\right.$ days decade $\left.{ }^{-1}\right)$, and autumn $\left(-1.459\right.$ days decade $\left.{ }^{-1}\right)$, and the weakest, though still significant, declines in winter $\left(-0.995\right.$ days decade $\left.{ }^{-1} ; p<0.05\right)$. Among the regions, however, there are differences with respect to the trends shown in the magnitude. For instance, in HES the frequency of the 90th percentile events declined at a lower rate compared to MES and, particularly, to LES; the same for the S compared to the $\mathrm{N}$; and for the EL with respect to the WL and the EQ. The region that experienced the strongest DPWG declines (see Table 1; e.g., HES $-0.093 \mathrm{~m} \mathrm{~s}^{-1}$ decade $^{-1}$ annually) are those with the weakest declines in the number of days exceeding the 90th percentile (Table 4; e.g., HES -2.834 days decade ${ }^{-1}$ annually). For HES, this means that the loss of DPWG magnitude is associated with declines in the weak to moderate wind gusts (i.e., days below those exceeding the 90th percentile). For 1975-2006 (Table S7), significant $(p<0.05)$ declines in the 90th percentile of DPWG dominated.

The annual and seasonal multidecadal variability of the number of days exceeding the 90th percentile of DPWG across all stations for 1941-2016 shown in Fig. 8 (Fig. S6 for monthly plots) slightly differs with respect to that displayed by the magnitude (see Fig. 4 and Fig. S3). This is as only two phases are identified: (i) an increase until mid-1950s, as also shown by the magnitude; but (ii) a clear slowdown of the 90th percentile frequency of DPWG since then until 2016, particularly annually and in spring, summer, and autumn. Moreover, the running trends of the frequency of the 90th percentile of DPWG shown in Fig. 9 also displays a dominance of significant negative trends, except nonsignificant positive trends in the 1960s and in the last decade for window length $<40$ years.

In Table 5 monthly trends in the frequency of DPWG during 1941-2016 are shown; Table S8 reports trends for 1975-2006. Overall, the frequency of the 90th percentile of wind gusts significantly $(p<0.05)$ declined throughout the year. As for the magnitude, we found a marked intra-annual cycle with the strongest declines between October and May (November -0.602 days decade ${ }^{-1}$ ) and the weakest ones from June till September (June -0.293 days decade ${ }^{-1} ; p<0.10$ ). In combination with the same trend cycle detected for the magnitude of DPWG, positive $r$ values in Fig. 10 show significant relationships between trends in both parameters, that is, the more negative trends in the frequency are associated with more weakening of the magnitude in DPWG. This monthly cycle is also discerned in the regions, highlighting, for example, MES, HES, and EL where the decline in the frequency of DPWG events in the 90th percentile is of less magnitude and significance (i.e., $p>0.10$ ) during the winter months, and positively correlates with the nonsignificant increases in the magnitude of DPWG. In contrast to the magnitude trends, the reported trends in the frequency of DPWG in the upper decline are greater in the LES than in the MES and the HES classes, in the $\mathrm{N}$ than in the $\mathrm{S}$ of the country, and in the WL than in the EQ and the EL.

TABLE 2. As in Table 1, but monthly.

\begin{tabular}{|c|c|c|c|c|c|c|c|c|c|c|c|}
\hline & All & $\mathrm{C}$ & I & LES & MES & HES & $S$ & $\mathrm{~N}$ & EL & EQ & WL \\
\hline an & $(-0.0$ & $(-0.114)$ & $-0.077)$ & $(-0.096)$ & $(-0.102)$ & $(-0.253)$ & $(-0.112)$ & $(-0.085)$ & $(-0.247)$ & $(-0.154)$ & $(-0.089)$ \\
\hline eb & $(-0$. & ( & $(-0.066)$ & $(-0.0$ & $(-0.095)$ & $(-0.2$ & & & $(-0$. & & $-0.074)$ \\
\hline Mar & $(-0.05$ & $(-0.064)$ & $(-0.0$ & $(-0.0$ & $(-0.0$ & $(-0$ & $(-1$ & $(-0$ & $(-0$ & $(-1$ & $(-0$. \\
\hline Apr & $(-0.0$ & $(-0.0$ & $(-0.0$ & $(-0.0$ & $(-0$. & & & $(-0$ & -0 & ) & $(-0$ \\
\hline גav & -0.0 & -0 & -0. & -0 & -0 & +0 & -0 & & +0 & & -0 \\
\hline un & -0.0 & + & -0 . & -0 . & -0 . & $(+0$ & -1 & -0 & +0 & & -0 \\
\hline al & -0.039 & & - & -0 . & -0.0 & & - & - & +0 & & -( \\
\hline Aug & -0.0 & - & -0 & -0 . & -0 & & - & - & +0 & $-c$ & -0.029 \\
\hline ep & $(-0.053)$ & $(-0.061)$ & -0.042 & $(-0.057)$ & -0.024 & +0.033 & -0.044 & $(-0$. & -0 & $(-0$ & $(-0.053)$ \\
\hline Oct & $(-0.084)$ & $(-0.092)$ & $(-0.073)$ & $(-0.084)$ & $(-0.084)$ & $(-0.1$ & $(-0.0$ & $(-0.0$ & -0 & $(-0$. & $(-0.083)$ \\
\hline . & $(-0.151)$ & $(-0.171)$ & $(-0.122)$ & $(-0.147)$ & $(-0.156)$ & $(-0.314)$ & & $(-0.121)$ & $(-0.334)$ & $(-0.203)$ & $(-0.140)$ \\
\hline Dec & $(-0.121)$ & $(-0.139)$ & $(-0.094)$ & $(-0.118)$ & $(-0.117)$ & $(-0.256)$ & $(-0.130)$ & $(-0.110)$ & $(-0.234)$ & $(-0.165)$ & $(-0.112)$ \\
\hline
\end{tabular}




\section{Trends in the mean of DPWG, 1941-2016}

(a) Annual

\begin{tabular}{|c|c|}
\hline $\mathrm{s}$ & $\begin{array}{l}-1 \\
\text { dec }^{-1} \text { ) }\end{array}$ \\
\hline & $>0.20$ \\
\hline & $0.15-0.20$ \\
\hline & $\begin{array}{l}0.10-0.15 \\
0.05-0.10\end{array}$ \\
\hline & $0.00-0.05$ \\
\hline & $0.00--0.05$ \\
\hline $\boldsymbol{\nabla}$ & $-0.05--0.10$ \\
\hline & $-0.10--0.15$ \\
\hline & $-0.15--0.20$ \\
\hline & $<-0.20$ \\
\hline
\end{tabular}

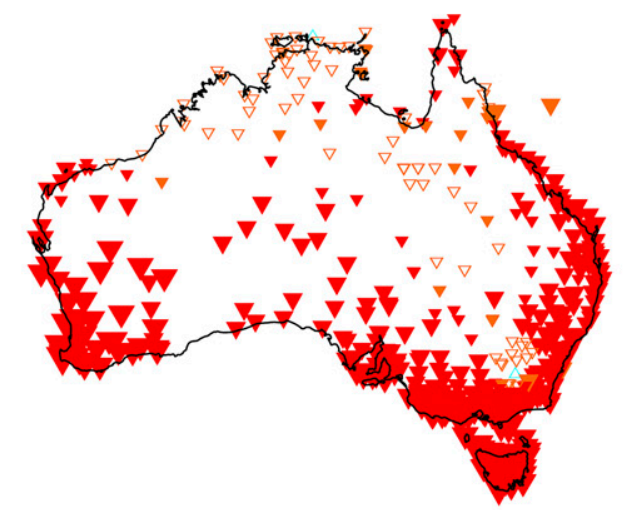

- Positive and significant at $p<0.05$

Positive and significant at $p<0.10$

$\triangle$ Positive and non-significant at $p<0.10$

$\nabla$ Negative and non-significant at $p<0.10$

$\nabla$ Negative and significant at $p<0.10$

$\nabla$ Negative and significant at $p<0.05$

(b) Winter (JJA)

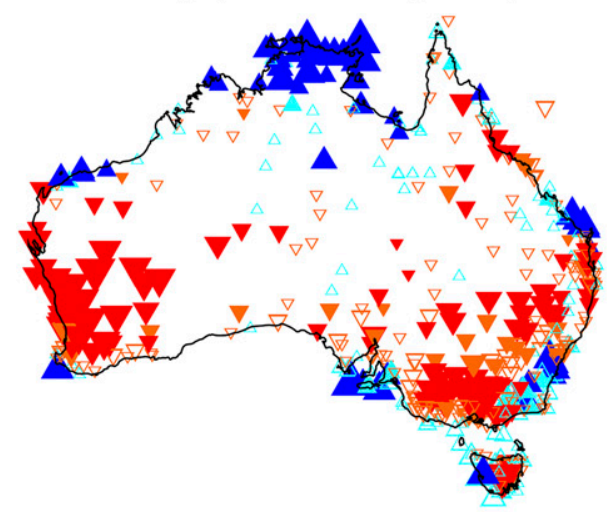

(d) Summer (DJF)

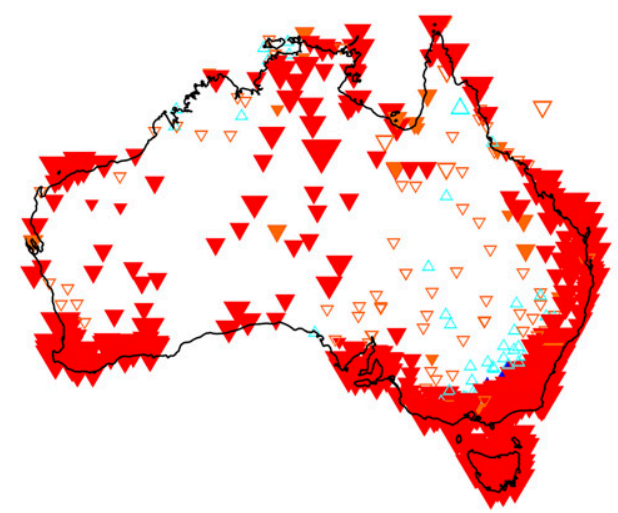

(c) Spring (SON)

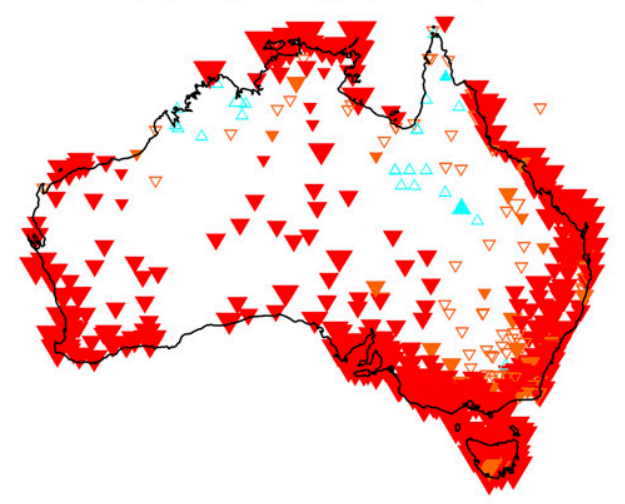

(e) Autumn (MAM)

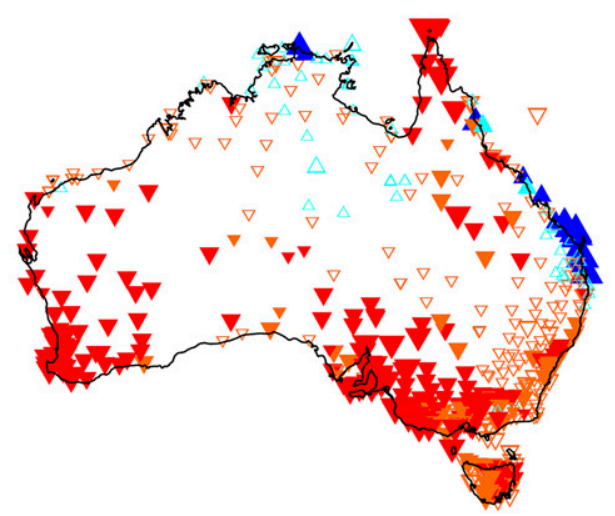

FIG. 6. Spatial distribution of the sign, magnitude $\left(\mathrm{m} \mathrm{s}^{-1}\right.$ decade $\left.^{-1}\right)$, and significance of annual and seasonal trends of mean DPWG for 548 stations across Australia for 1941-2016.

The spatial distribution of the 548 station based trends in the frequency of DPWG in the 90th percentile for 1941-2016 is shown in Fig. 11 and summarized in Table 3. Overall, we found almost the same pattern as for the magnitude, with a dominance of negative trends across Australia annually (Fig. 11a; $90.7 \%, 82.3 \%$ at $p<0.05)$. Similar results occur for all seasons
(Figs. 11c-e), with a lesser proportion of negative trends in winter (Fig. 11b). The consistency of the spatial trends in both the magnitude and frequency of DPWG is remarkable: for instance, the northern areas with increases in extreme winds in the 90th percentile in winter match with the positive trends shown in the magnitude (see Fig. 6b). The monthly spatial 
TABLE 3. Relative percentage (\%) of stations with significant (at $p<0.05$ and $p<0.10$ ) and nonsignificant (at $p>0.10$ ) negative and positive trends in the magnitude of DPWG and the 90th percentile frequency frequency of DPWG annually and seasonally for 1941-2016 for 548 stations across Australia. For the three $p$-level thresholds, relative frequencies are calculated with respect to the total number of stations showing negative or positive tendencies. Spatial distribution is shown in Fig. 6 (for the magnitude of DPWG) and Fig. 11 (for the 90th percentile of DPWG).

\begin{tabular}{|c|c|c|c|c|c|c|c|c|}
\hline & Negative & $\begin{array}{l}\text { Negative } \\
p<0.05\end{array}$ & $\begin{array}{l}\text { Negative } \\
p<0.10\end{array}$ & $\begin{array}{l}\text { Negative } \\
p>0.10\end{array}$ & Positive & $\begin{array}{l}\text { Positive } \\
p<0.05\end{array}$ & $\begin{array}{l}\text { Positive } \\
p<0.10\end{array}$ & $\begin{array}{c}\text { Positive } \\
p>0.10\end{array}$ \\
\hline \multicolumn{9}{|c|}{ Magnitude } \\
\hline Annual & 99.6 & 81.7 & 86.1 & 13.9 & 0.4 & 100.0 & 100.0 & 0.0 \\
\hline $\mathrm{DJF}$ & 61.5 & 32.6 & 42.1 & 57.9 & 38.5 & 29.9 & 36.5 & 63.5 \\
\hline SON & 95.4 & 79.5 & 85.7 & 14.3 & 4.6 & 0.0 & 8.0 & 92.0 \\
\hline JJA & 91.6 & 74.1 & 79.7 & 20.3 & 8.4 & 4.3 & 4.3 & 95.7 \\
\hline MAM & 85.8 & 43.8 & 55.3 & 44.7 & 14.2 & 21.8 & 24.4 & 75.6 \\
\hline \multicolumn{9}{|c|}{ Frequency } \\
\hline Annual & 90.7 & 82.3 & 85.9 & 14.1 & 9.3 & 19.6 & 31.4 & 68.6 \\
\hline DJF & 77.6 & 58.8 & 67.3 & 32.7 & 22.4 & 33.3 & 46.3 & 53.7 \\
\hline SON & 91.2 & 66.4 & 73.4 & 26.6 & 8.8 & 20.8 & 29.2 & 70.8 \\
\hline JJA & 84.7 & 70.9 & 76.1 & 23.9 & 15.3 & 19.0 & 23.8 & 76.2 \\
\hline MAM & 85.6 & 70.4 & 77.6 & 22.4 & 14.4 & 20.3 & 26.6 & 73.4 \\
\hline
\end{tabular}

distribution of the station-based trends in the frequency of DPWG in the upper decline (Fig. 12; summarized in Table S4b) is very conclusive as it displays the same distinct intra-annual pattern as for the magnitude. For 1975-2006, the same patterns for annual-seasonal (Fig. S7; Table S5b) and monthly (Fig. S8; Table S6b) results persists.

\section{d. Relationship with large-scale oceanic-atmospheric circulation modes}

Annual and seasonal $r$ values between the magnitude and the frequency of DPWG and the four oceanic-atmospheric circulation indices for all Australia and regional series show
Trends in the mean of DPWG, 1941-2016

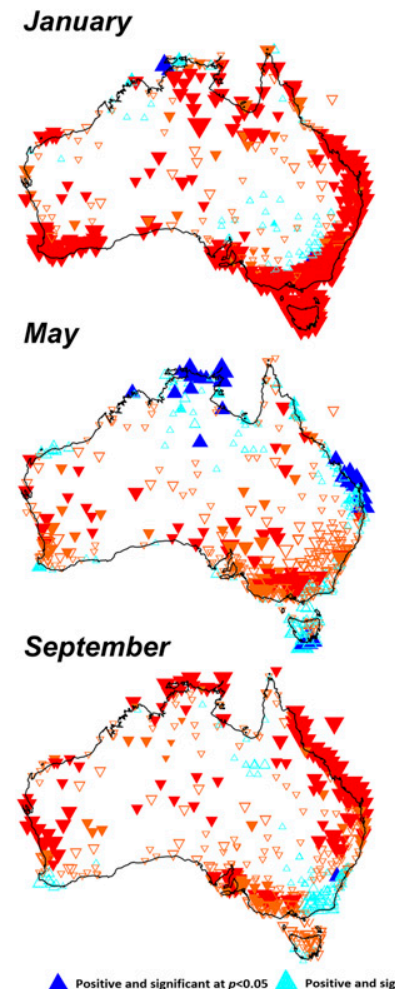

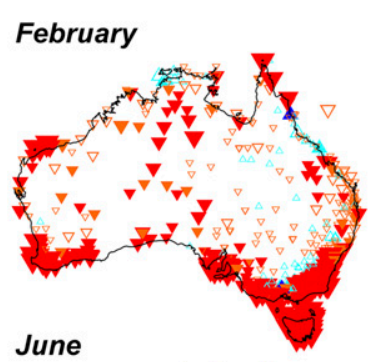

June
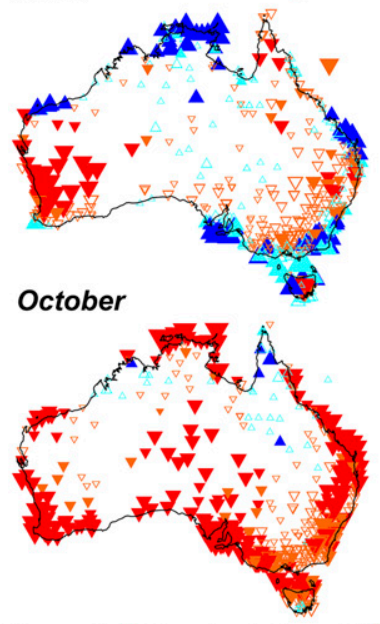
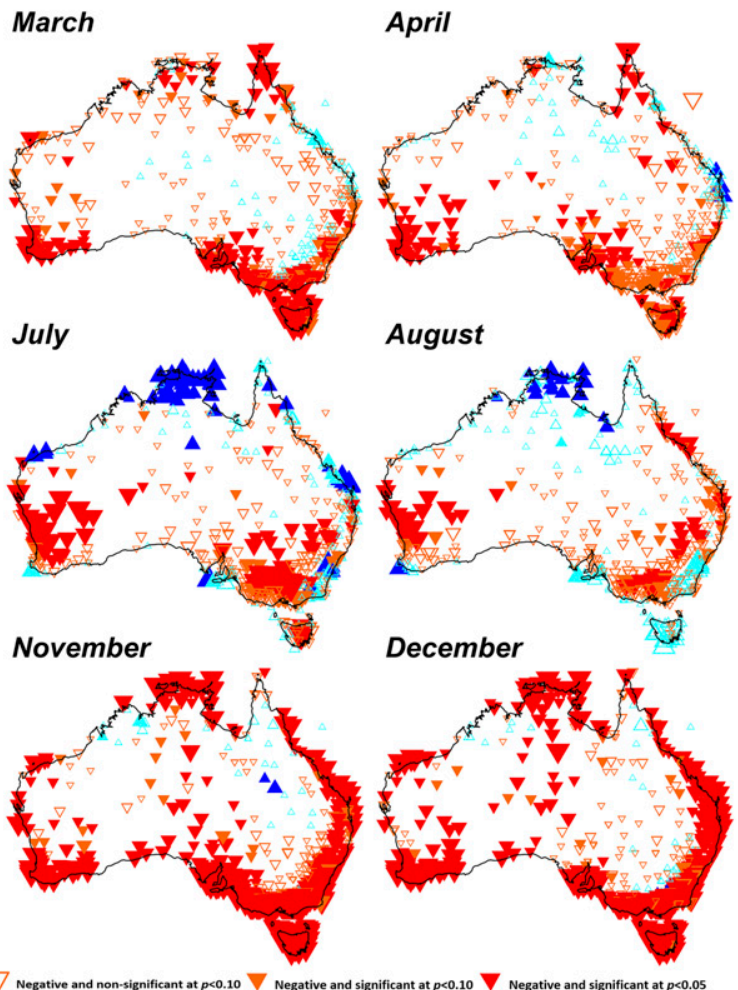

Trend
$\left(\mathrm{m} \mathrm{s}^{-1} \mathrm{dec}^{-1}\right)$

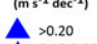

$\boldsymbol{A}$ A $0.10-0.15$ A $0.05-0.10$ o. $00 \cdot-0.05$ $\nabla \cdot 0.10 \cdot 0.15$ $\nabla \cdot 0.15 \cdot-0.20$

FIG. 7. As in Fig. 6, but monthly. 
TABLE 4. Annual and seasonal trends in the mean frequency of DPWG in the 90 th percentile (days decade ${ }^{-1}$ ) for all 548 stations and the regional series for 1941-2016. The columns to the right of "All" denote classes defined by four criteria and their locations and the number of stations in each is provided on Fig. 1. Statistically significant trends at $p<0.10$ are in bold and $p<0.05$ are bold and in parentheses.

\begin{tabular}{|c|c|c|c|c|c|c|c|c|c|c|c|}
\hline & All & $\mathrm{C}$ & I & LES & MES & HES & S & $\mathrm{N}$ & EL & EQ & WL \\
\hline Annual & $(-5.360)$ & $(-5.768)$ & $(-4.869)$ & $(-5.647)$ & $(-3.942)$ & $(-2.834)$ & $(-4.757)$ & $(-6.625)$ & $(-2.023)$ & $(-4.643)$ & $(-5.535)$ \\
\hline JJA & $(-0.995)$ & $(-0.948)$ & $(-1.025)$ & $(-1.075)$ & $(-0.669)$ & -0.223 & $(-0.859)$ & $(-1.167)$ & -0.007 & $(-0.781)$ & $(-1.043)$ \\
\hline SON & $(-1.246)$ & $(-1.405)$ & $(-1.111)$ & $(-1.338)$ & $(-0.915)$ & $(-0.821)$ & $(-1.187)$ & $(-1.613)$ & $(-0.777)$ & $(-1.215)$ & $(-1.278)$ \\
\hline DJF & $(-1.678)$ & $(-1.959)$ & $(-1.414)$ & $(-1.758)$ & $(-1.303)$ & $(-1.194)$ & $(-1.460)$ & $(-2.146)$ & $(-1.159)$ & $(-1.572)$ & $(-1.732)$ \\
\hline MAM & $(-1.459)$ & $(-1.463)$ & $(-1.328)$ & $(-1.494)$ & $(-1.074)$ & $(-0.603)$ & $(-1.270)$ & $(-1.717)$ & -0.109 & $(-1.082)$ & $(-1.490)$ \\
\hline
\end{tabular}

significant correlations, suggesting the role of some of these modes had in shaping DPWG variability.

For the magnitude of DPWG (Table 6), SAM, IOD, and MJO exhibited significant $(p<0.05)$ negative/positive relationship for all Australia ( $r$ values of $-0.59,-0.41$, and +0.38 , respectively) and each of the regional series (bar HES and EL for MJO) annually, while no significant $(p>0.10)$ correlations were found for either class with ENSO. Seasonally,

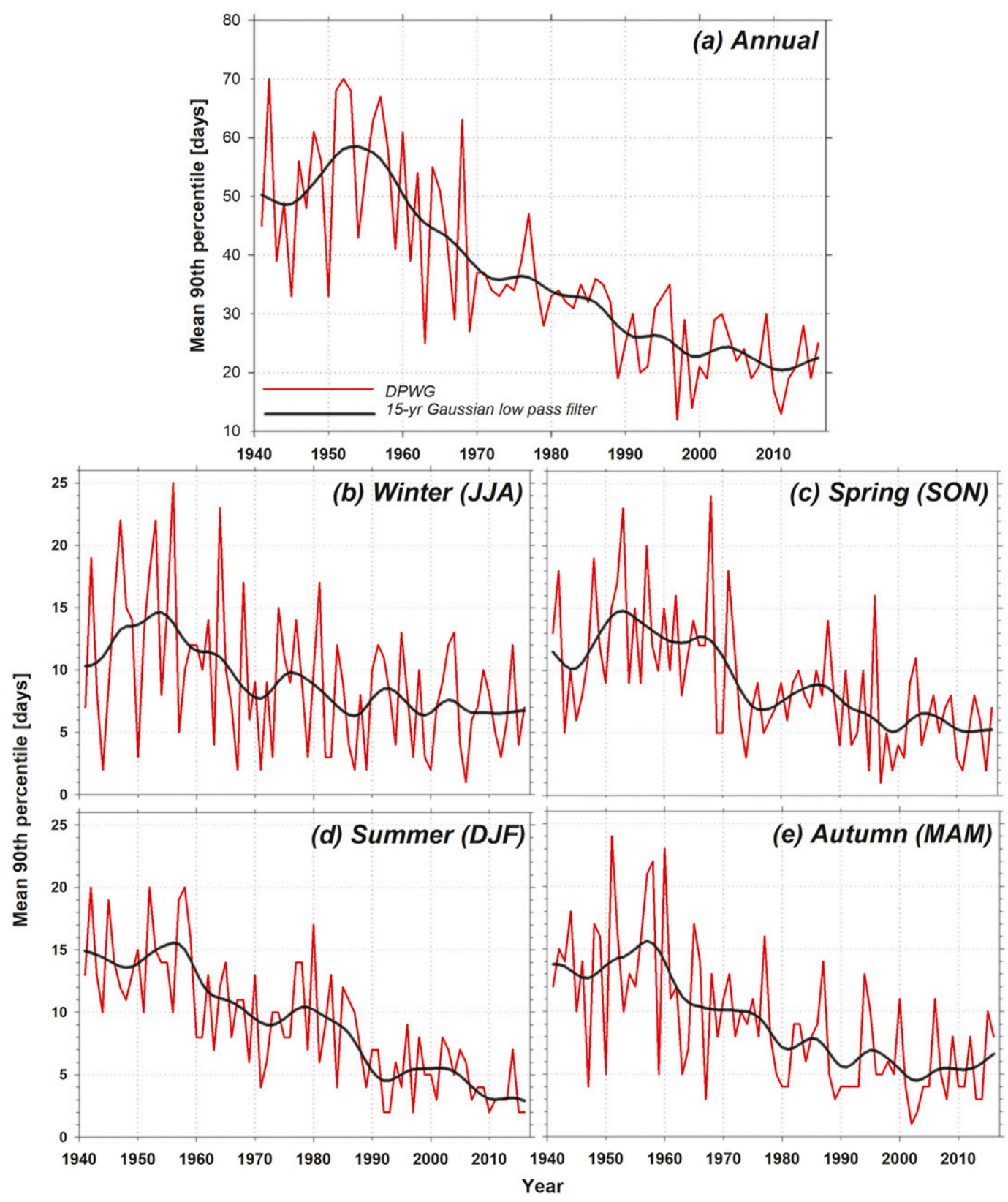

FIG. 8. Annual and seasonal mean in the number of days exceeding the 90th percentile in Australia for 1941-2016.

The 15-yr Gaussian low-pass filter is also shown with a black solid line. Monthly plots are shown in Fig. S6. 


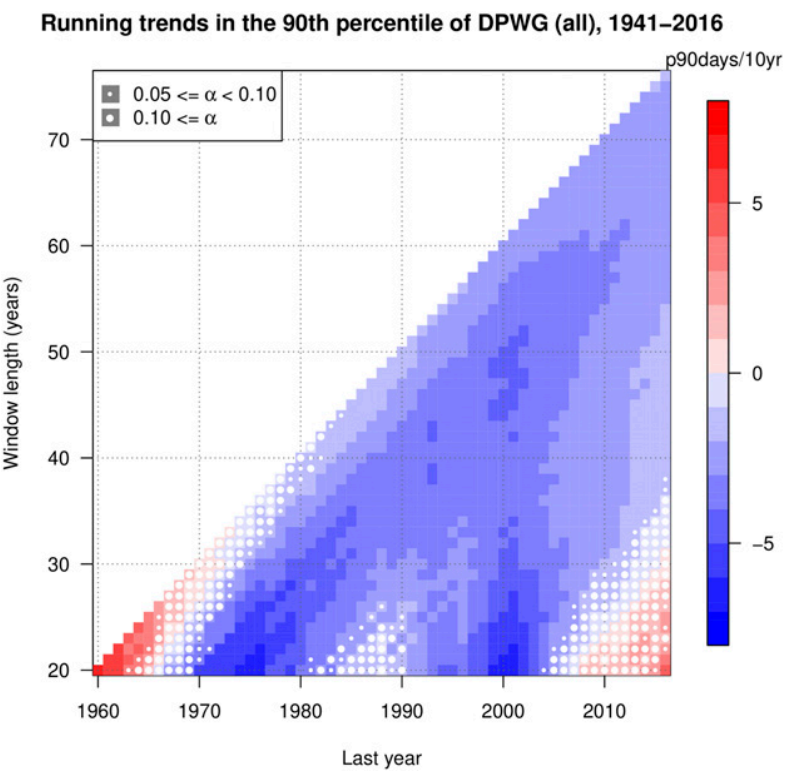

FIG. 9. Running trends of the number of days exceeding the 90th percentile in Australia for 1941-2016. White dots partially mask the nonsignificant (i.e., $p>0.10$ ) trends.

winter (SAM -0.58 and IOD -0.31$)$ and spring $(\mathrm{SAM}-0.54$ and IOD -0.26$)$ also showed most significant $(p<0.05)$ negative relationship with the magnitude of DPWG for all Australia and almost all the regional series. Further, summer SAM $(-0.24)$ and IOD $(-0.21)$ demonstrated significant $(p<$ 0.10) negative relationship with DPWG for all Australia and some regional series, whereas ENSO showed a widespread positive summer relationship $(+0.21, p<0.10)$. Last, in autumn significant negative/positive correlation was only found between SAM, IOD, and ENSO and DPWG for several regional series.

For the frequency of DPWG in the 90th percentile (Table 7), we also found that SAM $(-0.61)$ and IOD $(-0.40)$ exerted the strongest significant $(p<0.05)$ negative relationship for all Australia and each of the regional series. While ENSO and MJO showed weak and no statistically significant correlations.
Seasonally, winter frequency of DPWG in the 90th percentile demonstrated the strongest and significant $(p<0.05)$ correlations with SAM and $(-0.52)$ and IOD $(-0.41)$ for all Australia and most of the regional series, and less significant $(p<0.10)$ correlation with ENSO $(r-0.21)$. Similarly, spring (SAM -0.43 and IOD -0.26 ) and summer (SAM -0.27 and IOD -0.32 ) frequency of DPWG in the 90th percentile showed the most significant $(p<0.05)$ correlation for all Australia. Last, in autumn, only SAM showed significant relationship with mean frequency of DPWG in the 90th percentile for all Australia $(-0.28, p<0.05)$ and most of the regional series.

As inverse significant correlations between DPWG parameters and SAM and IOD dominate for almost all spatiotemporal scales, the tendency toward more positive phases of both oceanic-atmospheric circulation modes (see trends in Tables 6 or 7), could be partly behind the observed decline in both the magnitude and frequency of DPWG in the 90th percentile across Australia for 1941-2016.

\section{e. Potential physical processes associated with DPWG changes}

Figure 13 displays the long-term variability of large-scale horizontal pressure gradient between high- and low-latitude zones for 1948-2016. Annually, the pressure gradient displayed a significant decline $\left(-0.315 \mathrm{hPa}\right.$ decade $\left.^{-1}, p<0.05\right)$. Seasonally, we found significant $(p<0.05)$ weakening of horizontal pressure gradient for all seasons, except for a weak and nonsignificant decline in summer. The overall negative trend in the strength of the horizontal airflow is consistent with the reported slowdown in the magnitude and frequency of DPWG.

Figure 14 displays the spatial trends of geostrophic wind speed for Australia and surrounds for 1948-2016, and shows that annually, weakening geostrophic wind speeds (from -0.2 to $0.0 \mathrm{~m} \mathrm{~s}^{-1}$ decade $^{-1}$; Fig. 14a) were found over most of Australia, which is consistent with the widespread DPWG decreases; except over Tasmania where positive trends dominate. Seasonally, weak and mostly nonsignificant $(p>0.05)$ declines in winter geostrophic wind speed dominated (from -0.2 to $0.0 \mathrm{~m} \mathrm{~s}^{-1}$ decade $^{-1}$; Fig. $14 \mathrm{~b}$ ) with areas of positive and significant trends in the northern and southern regions (Southern Ocean and Tasmania). Spring also showed a dominance

TABLE 5. As in Table 4, but monthly.

\begin{tabular}{|c|c|c|c|c|c|c|c|c|c|c|c|}
\hline & All & $\mathrm{C}$ & I & LES & MES & HES & S & $\mathrm{N}$ & EL & EQ & WL \\
\hline & 0 & $-0.646)$ & 0508 & 576 & $0.476)$ & 381 ) & 5) & $-0.738)$ & $-0.391)$ & $-0.530)$ & $(-0.584)$ \\
\hline $\mathrm{eb}$ & I & & & & & & & & & & \\
\hline Iar & $(-0.5$ & $(-0.5$ & $(-0.4$ & $(-0$. & $(-0$ & $(-0$ & $(-$ & -0 & -0 & 3) & 15) \\
\hline 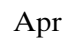 & $(-0$. & & & & & & & & & & \\
\hline Iay & $(-0$. & $(-$ & $(-$ & $(-1$ & & & & & & & \\
\hline un & -0.2 & -0.2 & -0.319 & $(-0$ & -0 & -1 & & & & & \\
\hline al & -0.322 & $(-0.3$ & -0.354 & $(-0.3$ & -0.218 & -0 & $(-$ & $(-$ & -0 . & -1 & $(-1$ \\
\hline Aug & $(-0.3$ & $(-0$ & $(-0$ & $(-0$ & -0 & -0 & & $(-$ & +0 & - & 50) \\
\hline ep & $(-0.252)$ & $(-0.319)$ & -0.197 & $(-0.303)$ & -0.129 & -0.088 & -0.185 & $(-0.3$ & -0.167 & $(-0.3$ & $(-0.266)$ \\
\hline ct & $(-0.392$ & $(-0.386)$ & $(-0.37$ & $(-0.415)$ & $(-0.2$ & $(-0.2$ & $(-0.3$ & $(-1$ & -0. & & $(-0.369)$ \\
\hline rov & $(-0.6$ & $(-0$. & $(-0$. & $(-0$ & $(-0$ & $(-0$ & & $(-0$ & $(-0$ & & $(-0$. \\
\hline Dec & $(-0.570)$ & $(-0.714)$ & $(-0.427)$ & $(-0.577)$ & $(-0.386)$ & $(-0.419)$ & $(-0.473)$ & $(-0.756)$ & $(-0.406)$ & $(-0.580)$ & $(-0.583)$ \\
\hline
\end{tabular}



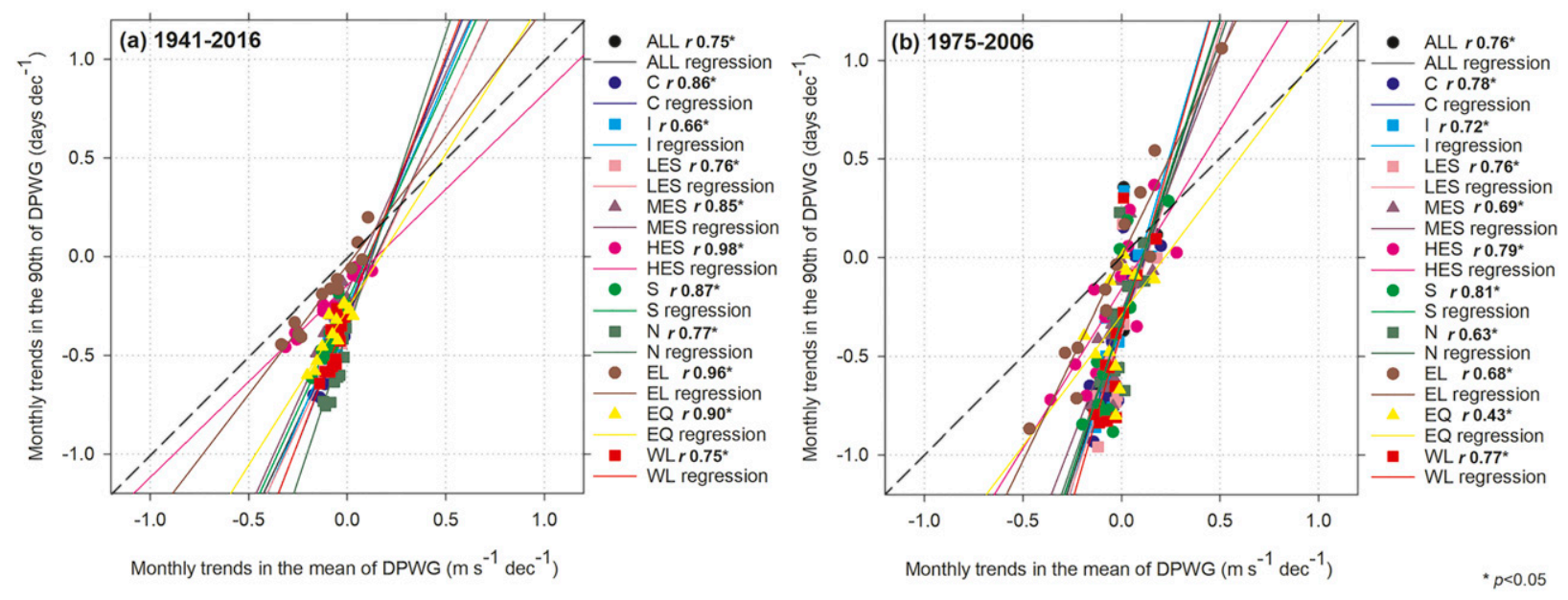

FIG. 10. Scatterplot of the relationship between monthly trends in the magnitude of DPWG and in the 90th percentile frequency of DPWG for all stations and for the different classes for (a) 1941-2016 and (b) 1975-2006. R-Pearson values (r) along with their statistical significance for each class are shown.

of nonsignificant $(p>0.05)$ negative trends in geostrophic wind speeds (from -0.2 to $0.0 \mathrm{~m} \mathrm{~s}^{-1}$ decade $^{-1}$; Fig. $14 \mathrm{c}$ ), except for increases in the southwest. Widespread areas showing negative trends of geostrophic wind occurred in summer (from -0.2 to $0.0 \mathrm{~m} \mathrm{~s}^{-1}$ decade $^{-1}$; Fig. 14d), being significant $(p<0.05)$ in Northern Territory-Queensland and Southern Ocean, except west Australia (from 0 to $+0.2 \mathrm{~m} \mathrm{~s}^{-1} \mathrm{decade}^{-1} ; p<0.05$ ). For autumn, geostrophic wind speed declined the most (from -0.3 to $0.0 \mathrm{~m} \mathrm{~s}^{-1}$ decade $^{-1}$; Fig. $\left.14 \mathrm{e}\right)$, significantly $(p<0.05)$ over the southeast. Overall, the dominance of negative geostrophic wind speed trends in continental surfaces match with the observed decline in DPWG; however, there are discrepancies among DPWG and geostrophic wind speed trends that could be linked to the shorter time period covered here (i.e., 19482016 instead of 1941-2016) or the complexity of mechanisms behind DPWG dynamics.

Apart from variations in nominal horizontal wind speed, vertical transport of atmospheric momentum changes is represented by trends of both the $A$ index (Fig. 15) and vertical wind shear (Fig. 16) for Australia and surrounds. Annually and seasonally (Fig. 15), a distinct spatial trend pattern of the atmospheric stratification thermodynamic instability was found; that is $A$ index declined in most of south Australia (down to -1.2 decade $^{-1}$ over Tasmania), and increased (from 0.0 to +0.6 decade $^{-1}$ ) in most of north Australia; with the exception of winter as negative $A$ index trends dominated across the country. These show part agreement with the DPWG trends pattern, as more significant and negative trends in extreme winds were found in southern Australia; in principle, declined $A$ index indicates more stable atmospheric conditions and lower magnitude and frequency of DPWG. Moreover, annual and seasonal (Fig. 16) trends in vertical wind shear do not show a clear spatial pattern, and, therefore, it is complex to relate to DPWG changes.

Last, annual and seasonal trends of ETC frequency and intensity around Australia are also investigated for 1975-2016 (Fig. 17). In general, ETC trends are quite weak. Both ETC frequency and intensity do not show statistically significant trends. Although a negative trend is observed around $45^{\circ} \mathrm{S}$, it is found only over the ocean. A significant trend in land is spatially heterogeneous.

\section{Discussion}

Climate studies focused on multidecadal variability and long-term trends in the magnitude and frequency of observed DPWG are very limited because of (i) low availability of historical time series and (ii) few approaches to quality control and homogenize observed DPWG data. We achieve this here by undertaking trend analysis over 548 homogenized DPWG time series across Australia derived by Azorin-Molina et al. (2019) covering 1941-2016 and the 1975-2006 subperiod for comparison purposes against McVicar et al. (2008). While the sparseness of the underlying observational network increases uncertainty in the earlier part of the record, continental trends are not appreciably different if restricted to those time series with greater than $80 \%$ or $90 \%$ completeness of observed data (Figs. S9 and S10).

Overall, our major finding showed a dominance of negative trends in DPWG for both periods, with a distinct seasonality: that is, significant declines dominated in SON, DJF, and MAM, and a weak and nonsignificant decline in JJA (which was even positive for 1975-2006 subperiod). These results are consistent with the declining trends in wind gusts reported by the majority (55\%) of the 20 studies reviewed by Azorin-Molina et al. (2016; see their Table 1). Moreover, this agrees with recent studies, for example, Vautard et al. (2019) who concluded that human-induced climate change has, to date, not impacted windstorms. Such observation-based findings disagree with climate model projections, which is not surprising as climate models fail to correctly simulate factors such as, for example, land surface changes (increase in surface roughness), or represent decadal variability (Vautard et al. 2019). Consequently, while it is currently not possible to generate projections of future storminess with high confidence (Walsh et al. 2016), 


\section{Trends in the 90th percentile of DPWG, 1941-2016}

\section{(a) Annual}
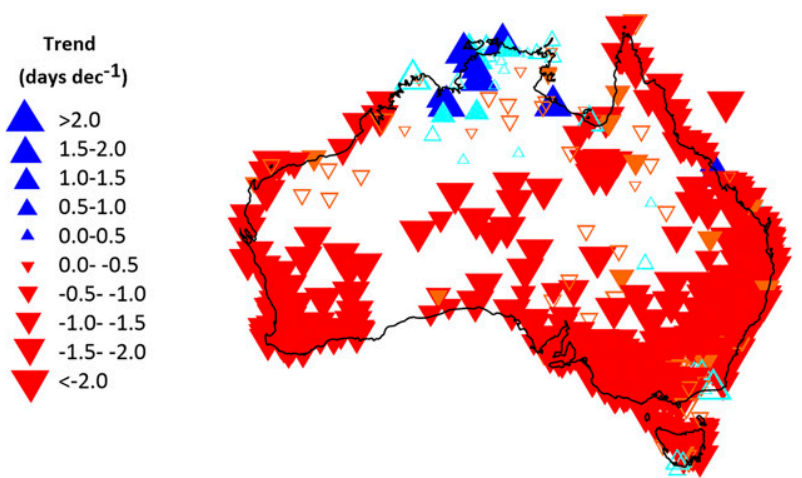

- Positive and significant at $p<0.05$

Positive and significant at $p<0.10$

$\triangle$ Positive and non-significant at $p<0.10$

$\nabla$ Negative and non-significant at $p<0.10$

$\checkmark$ Negative and significant at $p<0.10$

$\checkmark$ Negative and significant at $p<0.05$

(b) Winter (JJA)

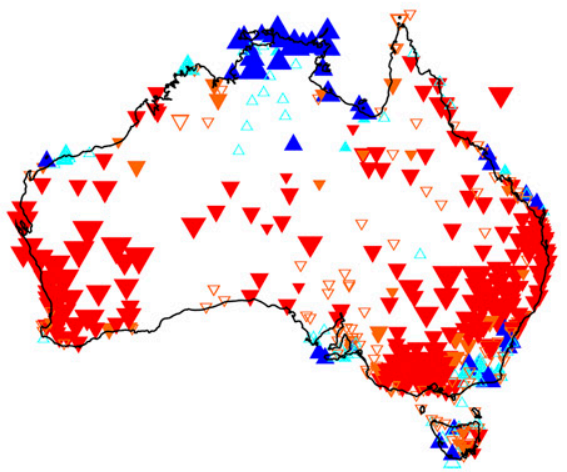

(d) Summer (DJF)

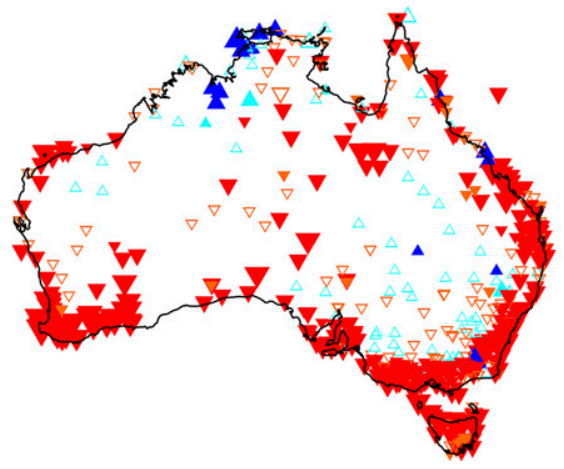

(c) Spring (SON)

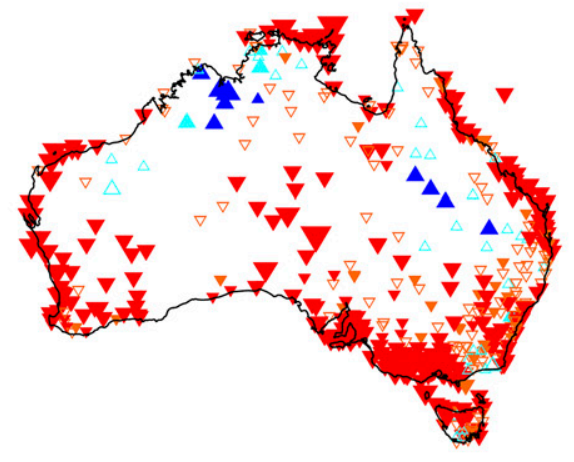

(e) Autumn (MAM)

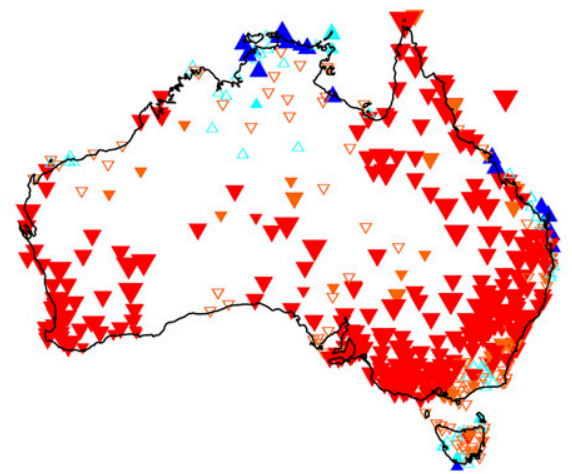

FIG. 11. Spatial distribution of the sign, magnitude (days decade ${ }^{-1}$ ), and significance of annual and seasonal trends of the number of days exceeding the 90th percentile DPWG for 548 stations across Australia for 1941-2016.

more observational studies like the one presented here are needed to assess and eventually attribute long-term past wind gust variability using high-quality homogenized data. Observations are the basis to knowing the past wind gust variability, to better understand the physical processes causing wind gusts, and to evaluate climate model simulations (Minola et al. 2020). Only after our collective knowledge base increases can better projections of changes in wind gust dynamics, needed for climate change adaptation, be produced.
Our results agree with previous Australian-focused research on extreme wind gust variability and thunderstorm activity. For instance, Alexander et al. (2011) also reported a reduction in the frequency of strong winds over southeast Australia during the twentieth century. Brown and Dowdy (2019) analyzed extreme wind gusts and thunderstorms in South Australia over 1979-2017 and found a decreased frequency in the far north of South Australia, except for locally increased risks around the southern Flinders Ranges and Yorke Peninsula regions. These 


\section{Trends in the 90th percentile of DPWG, 1941-2016}
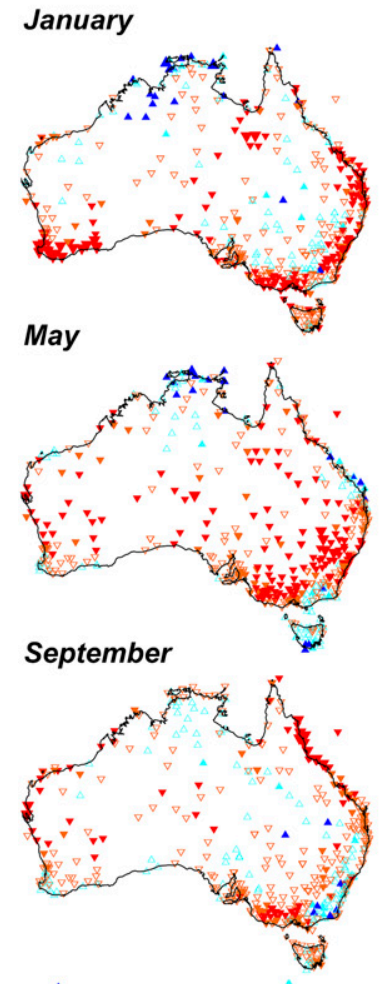

$\Delta$

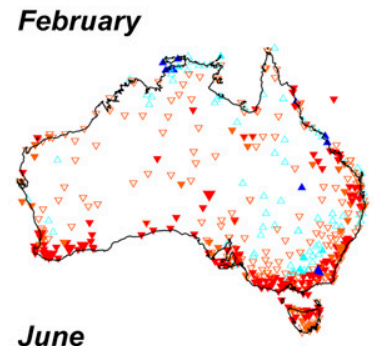

June

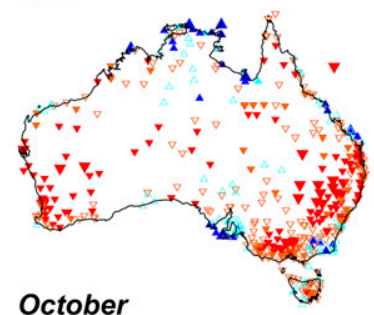

October

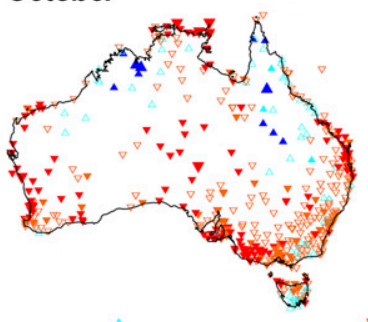

March

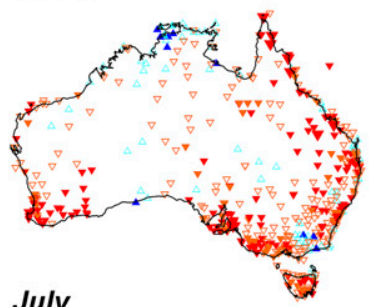

July

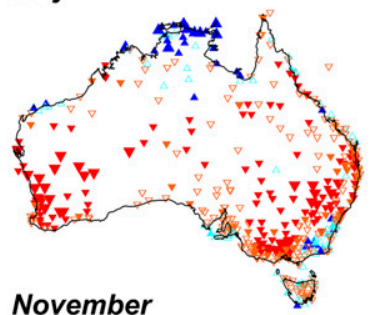

April
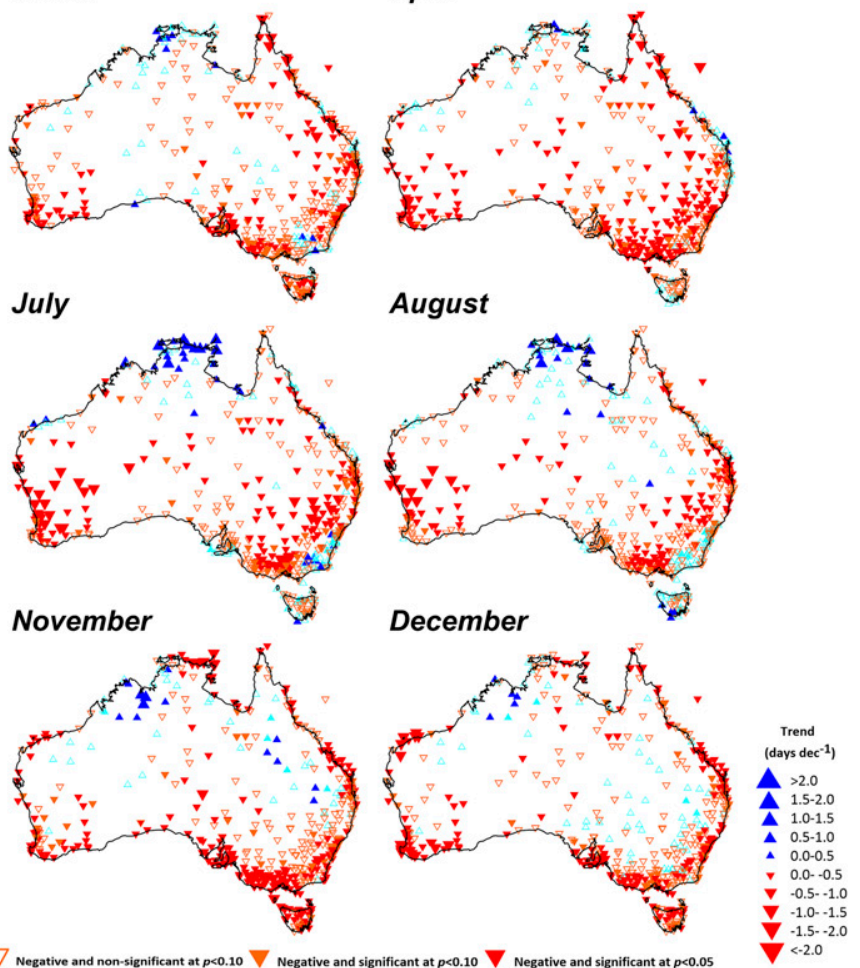

FIG. 12. As in Fig. 11, but monthly.

opposite trends found within the same regions supports our findings of the heterogeneity in the sign and magnitude of trends (Azorin-Molina et al. 2016), as the spatial and temporal variation of wind gusts are associated with different (complex) local, mesoscale, and synoptic mechanisms. Pepler (2020) found a longterm increase in anticyclones and decrease in cyclones; however, the assessment of the trends of severe thunderstorms and observed extreme wind gusts is challenging (IPCC 2013).

Declining trends of DPWG are of smaller magnitude $\left(-0.023 \mathrm{~m} \mathrm{~s}^{-1}\right.$ decade $\left.^{-1}\right)$ compared to mean wind speed $\left(-0.090 \mathrm{~m} \mathrm{~s}^{-1}\right.$ decade $\left.^{-1}\right)$ for the 1975-2006 subperiod used by McVicar et al. (2008) and Roderick et al. (2007). Also the widespread ( $88.6 \%$ of Australia) stilling reported by McVicar et al. (2008) is not shown for DPWG (60.9\% of stations) across Australia for 1975-2006. The seasonal variability detected nonsignificant increases in winter, which were also found by McVicar et al. (2008) for mean wind speed in northeastern Queensland. We also found that observed changes in DPWG vary among regions and elevation ranges; here we detected that changes in the magnitude of DPWG are greater in the high-elevation stations than in the mid- and low-elevation stations, whereas the frequency of DPWG declined at a lesser rate in high-elevation stations compared to mid- and lowelevation stations. This agrees with the findings shown by McVicar et al. (2010), Lin et al. (2013), and Zhang et al. (2020), and with the fact that wind variability is decoupled among atmospheric layers as found by Azorin-Molina et al. (2018b) below and above the trade wind inversion layers in the Canary Islands. Furthermore, the multidecadal Australia DPWG variability does not reflect the recent "recovery" of global mean wind speeds detected by Zeng et al. (2019) around 2010, which is in agreement with Azorin-Molina et al. (2019) who (i) reported for 2018 the most negative wind speed anomaly in Australia of the last 40 years and (ii) stated that strong winds still show a weak downward or stabilization trend. However, the positive running trends in the 90th percentile (see Fig. 9) observed in the last decade over window lengths $<30$ years could suggest an increase of extreme winds.

We also showed that DPWG changes are the result of internal decadal and multidecadal climate variability, as pointed out Zeng et al. (2019) for mean wind speed. The relationship between large-scale atmospheric circulation variability and the observed changes in DPWG has been scarcely analyzed; for example, Azorin-Molina et al. (2016) tracked it for the North Atlantic Oscillation index (NAO) and found significant correlations in winter in Spain and Portugal. In Australia, Brown and Dowdy (2019) found a strong relationship between the SAM and convective gust environments in winter and spring, but not with the ENSO and IOD. Dowdy (2016) already found that ENSO do not have a strong influence on thunderstorm activity in Australia, and Gillett et al. (2006), Hendon et al. (2007), and McVicar et al. (2008) associated mean wind speed 
TABLE 6. Trend (decade ${ }^{-1}$ ) of annual and seasonal ENSO (1941-2016), IOD (1941-2016), SAM (1957-2016), and MJO (1979-2016) and their Pearson's correlation coefficients with DPWG for all Australia and different groups. The columns to the right of "All" denote classes defined by four criteria, and their locations and the number of stations in each are provided in Fig. 1. Significant correlations were defined as those $p<0.10$ (in bold) and $p<0.05$ (in bold and in parentheses).

\begin{tabular}{|c|c|c|c|c|c|c|c|c|c|c|c|c|c|}
\hline & & Trend & All & $\mathrm{C}$ & I & LES & MES & HES & S & $\mathrm{N}$ & EL & EQ & WL \\
\hline \multirow[t]{5}{*}{ ENSO } & nnual & +0.04 & -0.08 & -0.09 & -0.06 & -0.08 & -0.09 & -0.04 & -0.09 & -0.06 & +0.06 & -0.03 & -0.09 \\
\hline & JJA & & & & & & & & & & & & -0.15 \\
\hline & SON & & -0.04 & -0.07 & +0.00 & 0.05 & .01 & 0.00 & -0.07 & -0.01 & .05 & 0.01 & -0.05 \\
\hline & DJF & +0.02 & +0.21 & +0.22 & +0.18 & -0.20 & +0.20 & $(+0.27)$ & +0.20 & +0.19 & $(-0.24)$ & +0.19 & +0.20 \\
\hline & MAN & & +0.02 & & +0.02 & +0.01 & +0.01 & +0.02 & +0.07 & -0.07 & & +0.06 & -0.00 \\
\hline \multirow[t]{5}{*}{ IOD } & Annual & $(+0.04)$ & $(-0.41)$ & $(-0.40)$ & $(-0.41)$ & $(-0.40)$ & $(-0.37)$ & $(-0.33)$ & $(-0.38)$ & $(-0.41)$ & $(-1$ & $(-0.36)$ & $(-0.41)$ \\
\hline & JJA & 5) & $-0.31)$ & $(-0.29)$ & $-0.33)$ & $(-0.33)$ & $(-0.30)$ & -0.19 & $(-0.30)$ & $(-0.29)$ & -0.09 & $(-0.26)$ & $(-0.32)$ \\
\hline & SON & $(+0.06)$ & $(-0.26)$ & $(-0.28)$ & -0.23 & -0.23 & $(-0.23)$ & -0.20 & $(-0.26)$ & $(-0.26)$ & -0.17 & -0.20 & $(-0.27)$ \\
\hline & DJF & $(+0.02)$ & -0.21 & -0.22 & -0.17 & -0.17 & -0.16 & -0.23 & -0.22 & -0.17 & $(-0.22)$ & $(-0.24)$ & -0.19 \\
\hline & $\mathrm{M}$ & & -0 . & -0 & -0.16 & -0.16 & -0.07 & -0 & -0.08 & $(-1$ & -( & -1 & -0.18 \\
\hline \multirow[t]{5}{*}{ SAM } & Annual & $(+0.21)$ & $(-0.59)$ & $(-0.58)$ & $(-0.59)$ & $(-0.58)$ & $(-0.63)$ & $(-0.57)$ & $(-0.61)$ & $(-0.51)$ & $(-0.49)$ & $(-0.59)$ & $(-0.59)$ \\
\hline & JJA & +0.14 & $(-0.58)$ & $(-0.56)$ & $(-0.61)$ & $(-0.59)$ & $(-0.51)$ & $(-0.39)$ & $(-0.58)$ & $(-0.52)$ & -0.21 & $(-0.49)$ & $(-0.60)$ \\
\hline & SON & +0.04 & $(-0.54)$ & $(-0.51)$ & $(-0.56)$ & $(-0.52)$ & $(-0.61)$ & $(-0.66)$ & $(-0.58)$ & $(-0.43)$ & $(-0.56)$ & $(-0.59)$ & $(-0.51)$ \\
\hline & DJF & $(+0.42)$ & -0.24 & -0.26 & -0.18 & -0.23 & -0.19 & -0.26 & -0.25 & -0.20 & -0.24 & $(-0.22)$ & -0.23 \\
\hline & MAM & $(+0.27)$ & -0.20 & -0.19 & -0.22 & -0.22 & -0.17 & -0.04 & -0.22 & -0.15 & -0.02 & -0.09 & -0.23 \\
\hline \multirow[t]{5}{*}{ MJO } & Annual & +0.01 & $(+0.38)$ & $(+0.34)$ & $(+0.43)$ & $(+0.39)$ & $(+0.37)$ & +0.26 & $(+0.33)$ & $(+0.46)$ & +0.07 & +0.28 & $(+0.41)$ \\
\hline & JJA & +0.04 & -0.02 & & -0.03 & -0.02 & & & & & & & -0.01 \\
\hline & SON & -0.03 & 0.09 & +0.10 & +0.08 & +0.09 & & +0.08 & +0.09 & +0.08 & +0.16 & +0.09 & +0.08 \\
\hline & DJF & +0.02 & 0.05 & +0.08 & 0.00 & 0.03 & +0.05 & +0.14 & +0.07 & 0.00 & +0.11 & +0.06 & +0.04 \\
\hline & MAM & -0.06 & -0.06 & -0.05 & -0.06 & -0.04 & -0.11 & -0.15 & -0.08 & 0.00 & -0.17 & -0.09 & -0.04 \\
\hline
\end{tabular}

with the role played by SAM. Our results agree with these findings as observed DPWG changes are significantly modulated by large-scale modes of variability such as SAM, IOD, and MJO, but not with the ENSO. We also analyzed the potential physical processes relating to atmospheric circulation change influences DPWG, following the same approach as Zhang et al. (2020). The overall decreased large-scale pressure gradient between high and low latitudes and regional pressure- gradient force (geostrophic wind at $850 \mathrm{hPa}$ ) indicated the weakened horizontal airflow; consistent with the observed DPWG decline. Previous studies have also found the key role of pressure gradient in regulating mean wind speed (Lin et al. 2013; Li et al. 2018) and maximum wind speed in China (Zhang et al. 2020). Moreover, the change of vertical transport of atmospheric momentum was investigated herein, being represented by atmospheric thermal stratification instability

TABLE 7. As in Table 6, but in the mean frequency of DPWG in the 90th percentile.

\begin{tabular}{|c|c|c|c|c|c|c|c|c|c|c|c|c|c|}
\hline & & Trend & All & $\mathrm{C}$ & I & LES & MES & HES & $S$ & $\mathrm{~N}$ & EL & EQ & WL \\
\hline \multirow[t]{5}{*}{ ENSO } & Annual & +0.04 & -0.04 & -0.05 & -0.02 & +0.03 & +0.01 & -0.08 & -0.06 & -0.09 & +0.19 & +0.01 & -0.04 \\
\hline & JJA & +0.04 & -0.21 & -0.23 & $(-0.23)$ & -0.21 & -0.18 & -0.05 & -0.20 & -0.22 & -0.03 & -0.11 & -0.20 \\
\hline & SON & +0.07 & +0.00 & -0.02 & +0.03 & +0.01 & +0.04 & +0.04 & +0.00 & -0.02 & +0.01 & +0.03 & +0.01 \\
\hline & DJF & +0.02 & +0.14 & +0.15 & +0.10 & +0.15 & +0.07 & +0.14 & +0.12 & +0.14 & & .15 & +0.14 \\
\hline & MAN & +0.03 & +0.03 & +0.01 & +0.05 & +0.04 & +0.07 & +0.13 & +0.01 & -0.03 & +0.24 & +0.05 & +0.03 \\
\hline \multirow[t]{5}{*}{ IOD } & Annual & $(+0.04)$ & $(-0.40)$ & $(-0.38)$ & $(-0.40)$ & $(-0.41)$ & $(-0.31)$ & $(-0.24)$ & $(-0.35)$ & $(-0.44)$ & -0.12 & $(-0.37)$ & $(-0.39)$ \\
\hline & JJA & $(+0.05)$ & $(-0.41)$ & $(-0.41)$ & $(-0.41)$ & $(-0.42)$ & $(-0.38)$ & $(-0.24)$ & $(-0.38)$ & $(-0.39)$ & +0.01 & 31) & $(-0.40)$ \\
\hline & SON & $.06)$ & $(-0.26)$ & $(-0.23)$ & -0.23 & $(-0.26)$ & -0.20 & -0.15 & -0.22 & $(-0.34)$ & -0.10 & $(-0.23)$ & $(-0.25)$ \\
\hline & DJF & $(+0.02)$ & $(-0.32)$ & $(-0.27)$ & -0.21 & $(-0.28)$ & -0.22 & -0.20 & $(-0.23)$ & $(-0.27)$ & -0.20 & -0.20 & $(-0.25)$ \\
\hline & MAN & $(+0.03)$ & -0.13 & -0.12 & -0.13 & +0.13 & -0.04 & -0.02 & -0.06 & $(-0.28)$ & +0.03 & -0.08 & -0.14 \\
\hline \multirow[t]{5}{*}{ SAM } & Annu & $(+0.21)$ & $(-0.61)$ & $(-0.62)$ & $(-0.57)$ & $(-0.59)$ & $(-0.61)$ & $(-0.58)$ & $(-0.63)$ & $(-0.59)$ & $(-0.42)$ & $(-0.64)$ & $(-0.62)$ \\
\hline & JJA & +0.14 & $(-0.52)$ & $(-0.52)$ & $(-0.57)$ & $(-0.52)$ & $(-0.51)$ & $(-0.47)$ & $(-0.56)$ & $(-0.53)$ & -0.22 & $(-0.48)$ & $(-0.54)$ \\
\hline & SON & +0.04 & $(-0.43)$ & $(-0.45)$ & $(-0.52)$ & $(-0.43)$ & $(-0.55)$ & $(-0.60)$ & $(-0.51)$ & $(-0.38)$ & $(-0.52)$ & $(-0.51)$ & $(-0.46)$ \\
\hline & DJF & $(+0.42)$ & $(-0.27)$ & $(-0.30)$ & -0.17 & -0.24 & -0.16 & -0.16 & -0.20 & $(-0.31)$ & $(-0.28)$ & -0.19 & $(-0.26)$ \\
\hline & MAI & $(+0.27)$ & $(-0.28)$ & -0.25 & $(-0.26)$ & $(-0.30)$ & $(-0.29)$ & -0.16 & -0.23 & $(-0.32)$ & -0.09 & $(-0.27)$ & $(-0.29)$ \\
\hline \multirow[t]{5}{*}{ MJO } & Annual & +0.01 & 0.10 & 0.19 & 0.05 & 0.14 & 0.05 & 0.08 & 0.16 & 0.24 & 0.02 & 0.14 & 0.19 \\
\hline & JJA & +0.04 & -0.17 & -0.10 & -0.18 & -0.13 & -0.11 & 0.04 & -0.06 & -0.13 & 0.05 & -0.11 & -0.14 \\
\hline & SON & -0.03 & -0.03 & -0.06 & -0.13 & -0.03 & -0.10 & -0.12 & -0.08 & -0.05 & 0.06 & 0.00 & -0.05 \\
\hline & DJF & +0.02 & -0.06 & -0.04 & -0.08 & -0.06 & -0.04 & 0.08 & -0.02 & -0.10 & 0.04 & -0.01 & -0.06 \\
\hline & MAM & -0.06 & -0.24 & -0.19 & -0.16 & -0.25 & -0.18 & -0.26 & -0.11 & -0.14 & -0.18 & -0.17 & -0.22 \\
\hline
\end{tabular}




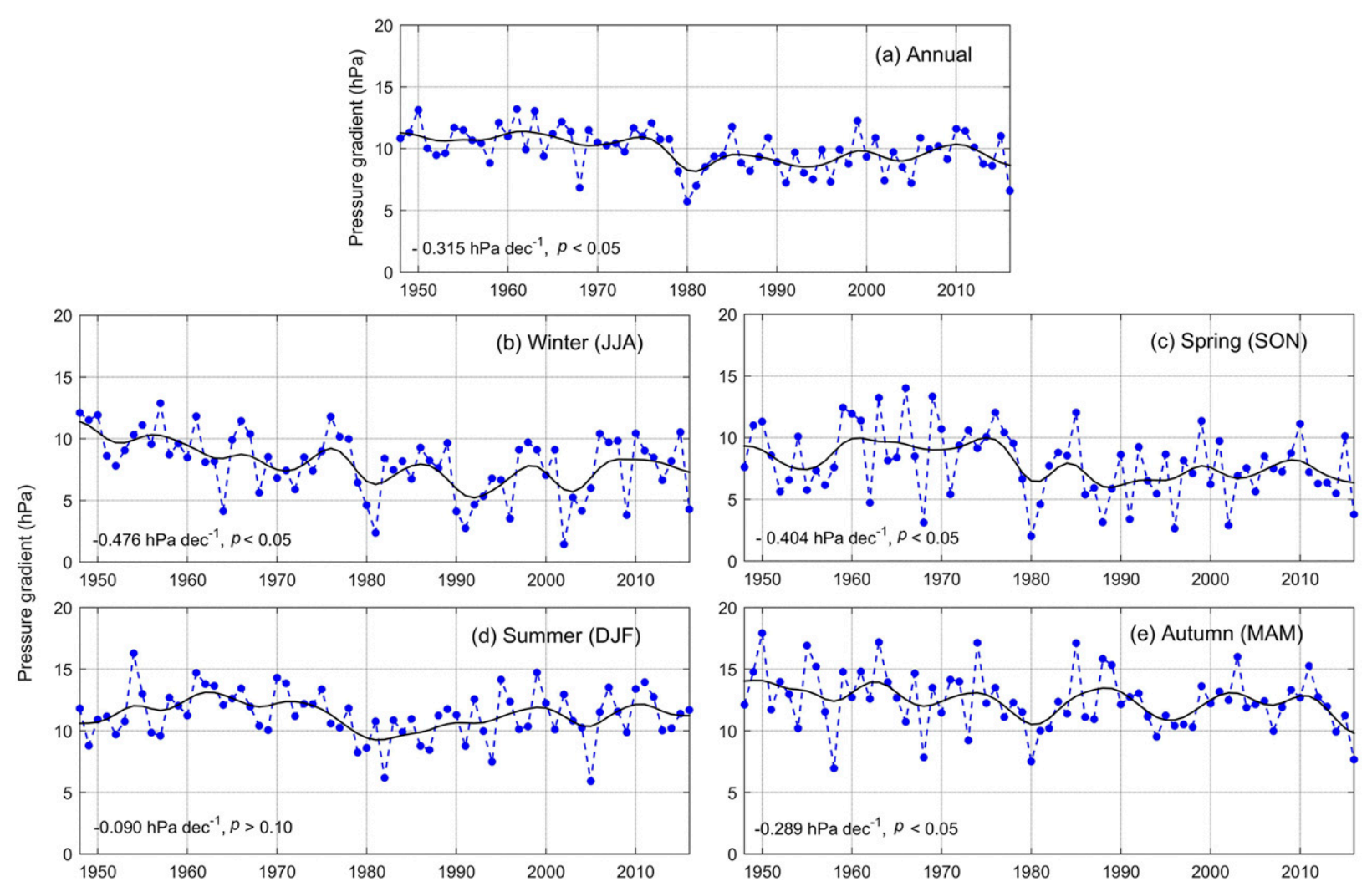

FIG. 13. Annual and seasonal large-scale horizontal pressure gradient between high and low latitudes for 1948-2016. The 11-yr Gaussian low-pass filter (solid line) highlights multidecadal variability. Decadal trends $\left(\mathrm{hPa} \mathrm{decade}^{-1}\right)$ and statistical significance are also displayed in each plot.

( $A$ index $)$ and vertical wind shear. Overall, declined atmospheric thermal stratification instability in southern Australia and vertical wind shear in part of Australia showed weakened vertical momentum transport from the middle and lower troposphere to surface, which is also supported by the reduced frequency of days with convective environments (Dowdy 2020). Additionally, trends in the frequency and intensity of ETCs were weak, and they do not explain the observed DPWG changes. To summarize: the precise attribution of the causes behind the observed changes in DPWG is a challenging task in climate research as wind gusts are driven by local-to-mesoscale mechanisms (e.g., orography, sea surface temperatures, differential heating, among many others), large-scale atmospheric circulation modes, and the recent influence of human-induced climate changes. The results and datasets of the current study are highly valuable for the evaluation of wind related hazard risks to different socioeconomic and environmental sectors, such as wind driven fires, health, energy, finance/insurance, and climate adaptation, among others (Brown and Dowdy 2019; BorchersArriagada et al. 2020)

A next logical step in our research would be to focus on assessing and attributing most damaging winds. The probability of exceedance of DPWG shown in Fig. S11 reveals that the occurrence of wind gusts has not changed for 1941-2016. However, maxima of DPWG (Figs. S12 and S13) showed opposite positive yet not significant $(p>0.10)$ trends compared to the declining tendency shown by the mean and the 90th percentile. Another future work in our research would be to develop a historical daily gridded product of DPWG covering all Australia to better know the areas and time of the year most likely to experience strong winds; similar to the product created by (McVicar et al. 2008) for daily near-surface mean wind speeds grids at a $0.01^{\circ}$ spatial resolution across Australia (available at https://doi.org/10.25919/5c5106acbcb02; last accessed 27 November 2020). However, interpolating extreme winds with high reliability is a challenging task due to (i) the local and short-lived nature of wind gusts (ii) and the lower density of the observation network relative to that for air temperature and precipitation, especially before 2003. Further advances in the interpolation of extreme winds are strongly needed, as producing such data will assist understanding how DPWG might change in the future due to the anthropogenic climate change. Last, projected changes to mean surface wind speeds showed declines in Australia (Evans et al. 2018), and large uncertainties in the magnitude and sign of future wind gusts exist (CSIRO and BoM 2015). This limit is embodied in the design of regional and global climate models that, due to their coarse horizontal spatial resolution, cannot explicitly resolve turbulent eddies involved in the gustiness, which is then parameterized (Gutiérrez et al. 2020). Gusts originated by finer-scale surface features (e.g., sea breezes and mountain effects; Prein et al. 2015) and extreme winds associated with 
(a) Annual

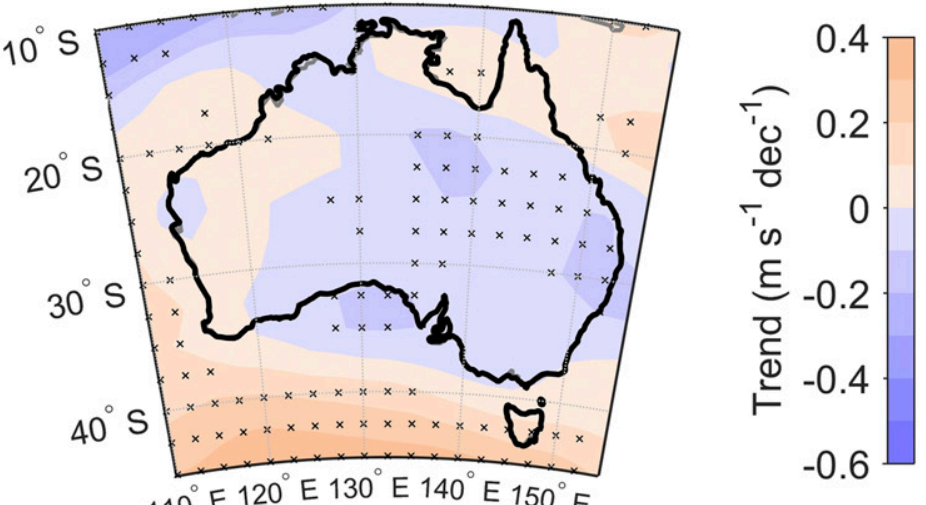

(b) Winter (JJA)

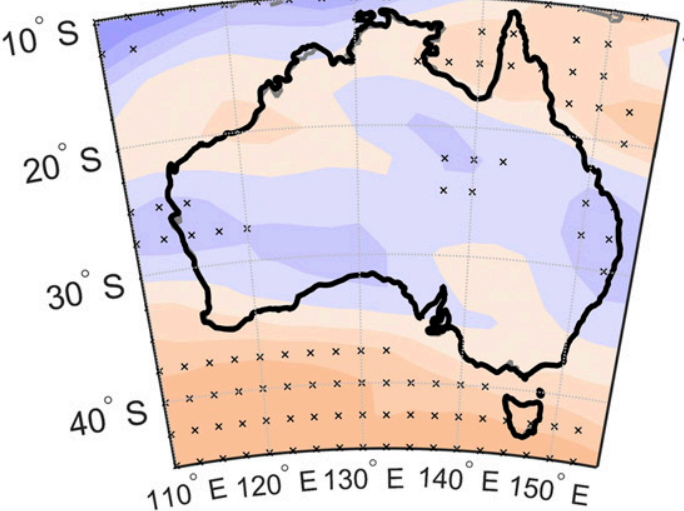

(d) Summer (DJF)

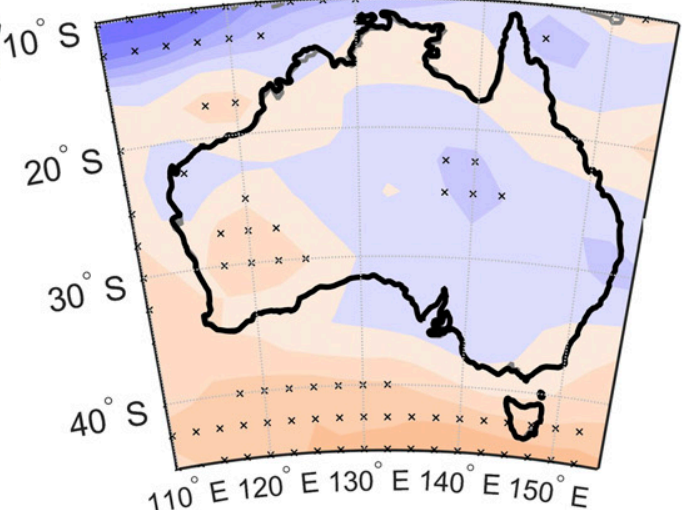

(e) Autumn (MAM)
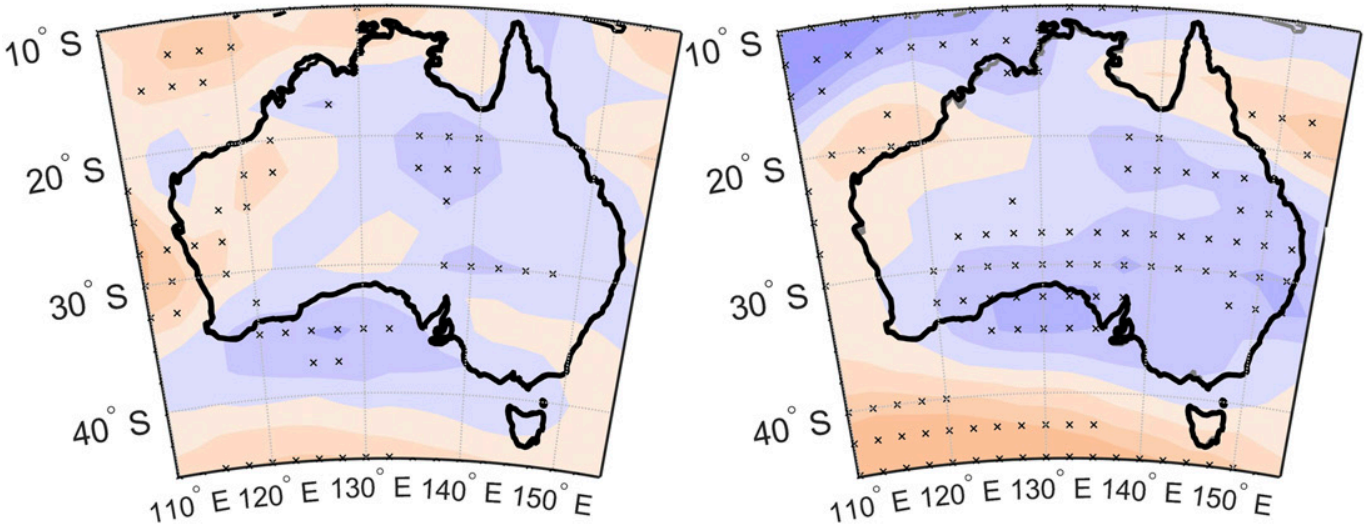

FIG. 14. Annual and seasonal spatial distribution of geostrophic wind speed trends $\left(\mathrm{m} \mathrm{s}^{-1} \mathrm{decade}^{-1}\right)$ across Australia and surroundings for $1948-2016$. A small black x represents a $2.5^{\circ} \times 2.5^{\circ}$ grid cell with a significant trend at $p<0.05$.

the deep convective systems (e.g., Clarke et al. 2019) are missed or not well represented in the current models.

\section{Conclusions}

The principal findings of this study of the long-term (19412016) and multidecadal variability of daily peak wind gusts (DPWG) from 548 stations across Australia are as follows:
1) The magnitude of DPWG declined significantly $(p<0.05)$ for 1941-2016 $\left(-0.067 \mathrm{~m} \mathrm{~s}^{-1}\right.$ decade $\left.^{-1}\right)$, showing a distinct seasonal cycle with the strongest declines in summer, followed by spring and autumn (i.e., September-April) and then winter (i.e., JuneAugust), which has no significant trend. For the 1975-2006 subperiod, almost the same seasonal pattern occurred, with a weak and nonsignificant $(p>0.10)$ positive trends in winter. 
(a) Annual

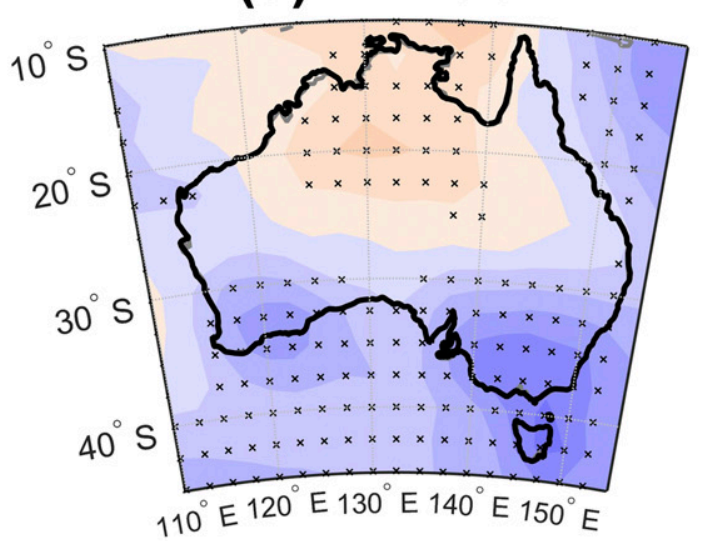

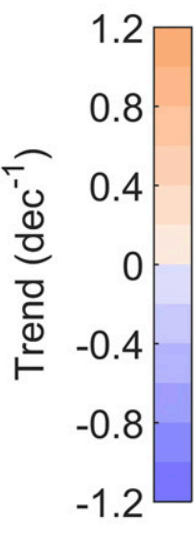

(c) Spring (SON)

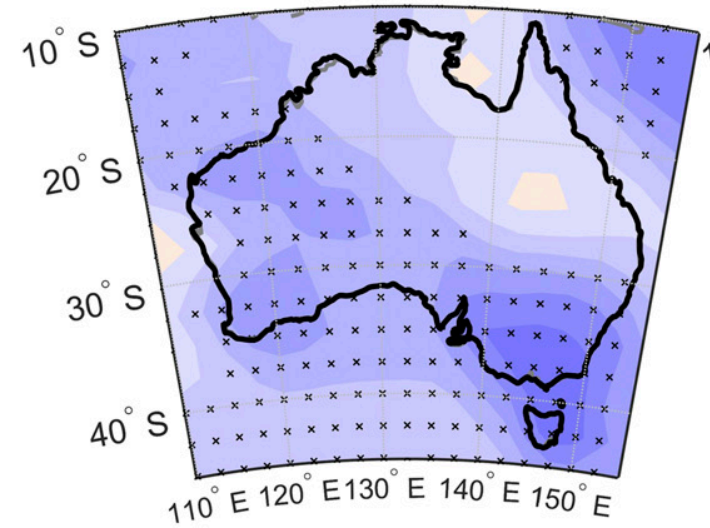

(d) Summer (DJF)

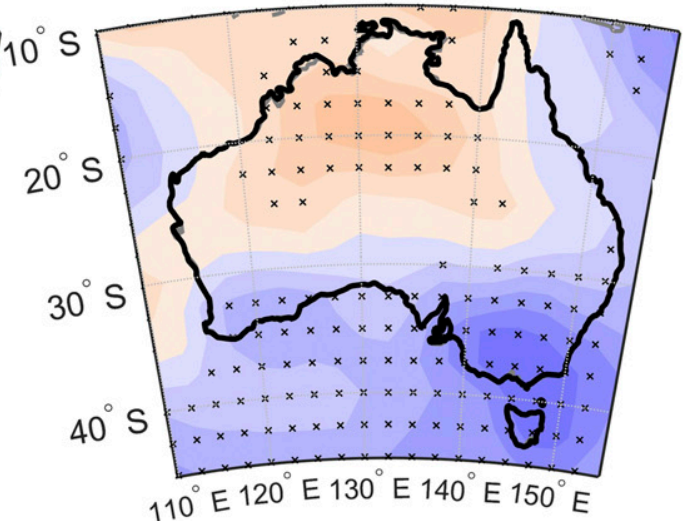

(e) Autumn (MAM)

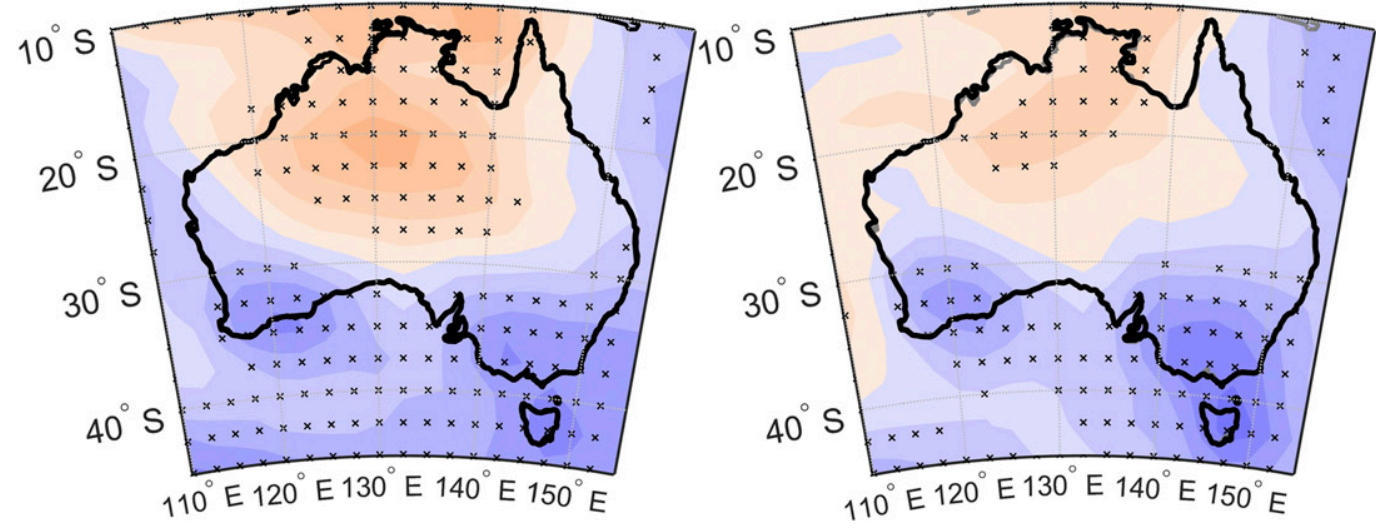

FIG. 15. Annual and seasonal spatial distribution of the sign and magnitude and associated statistical significance of the atmospheric thermal stratification $(A$ index $)$ trends across Australia and surroundings for 1948-2016. A small black $x$ represents a $2.5^{\circ} \times 2.5^{\circ}$ grid cell with a significant trend at $p<0.05$.

2) The frequency of DPWG exceeding the 90th percentile declined at a rate of -5.360 days decade ${ }^{-1}(p<0.05)$ over 1941-2016. As for the magnitude, extreme winds in the 90th percentile showed a marked intra-annual cycle with significant $(p<0.05)$ declines in spring, summer, and autumn
(September till May) and the weakest declines in winter (i.e., June-August). The same weakening trend in the 90th percentile was found for 1975-2006.

3) Observed changes in the magnitude and frequency of DPWG vary among regions. For instance, at high-elevation 
(a) Annual

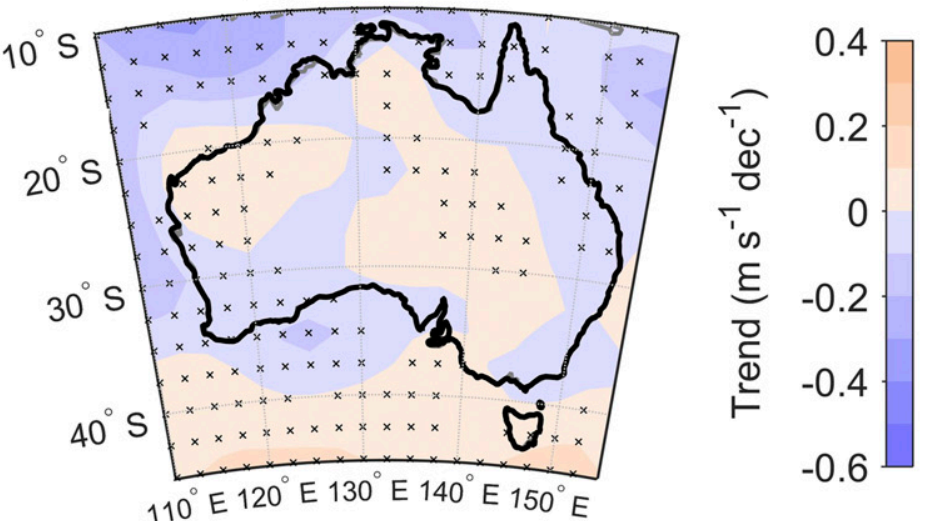

(b) Winter (JJA)

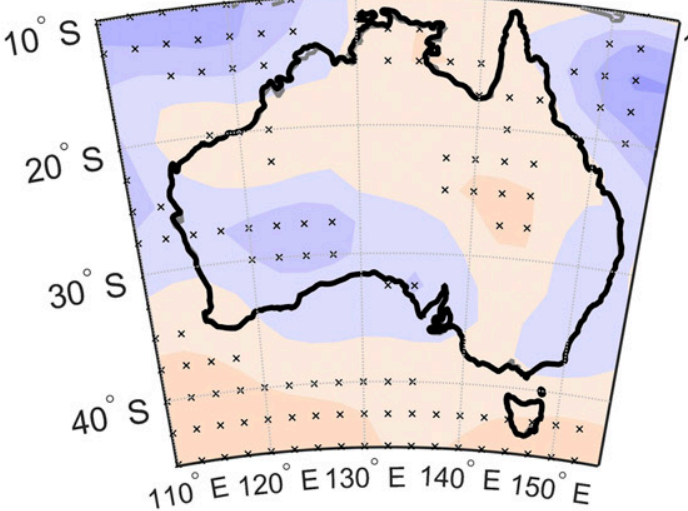

(d) Summer (DJF)

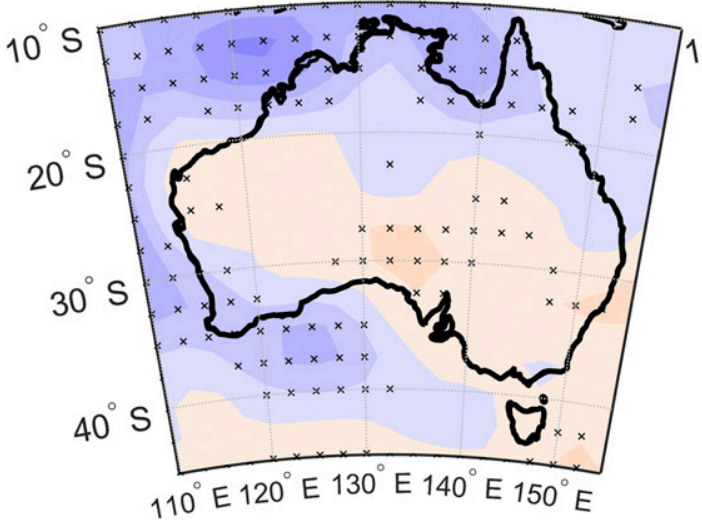

(c) Spring (SON)

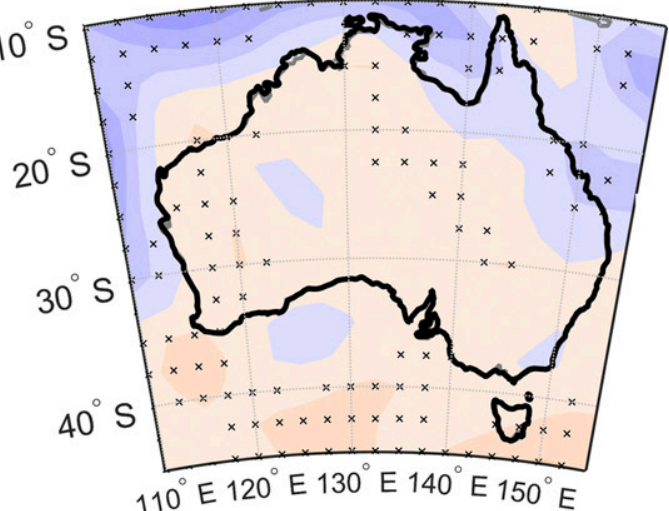

(e) Autumn (MAM)

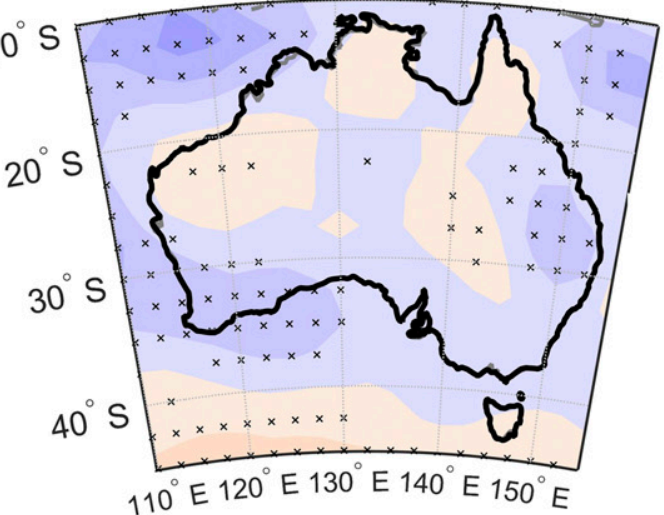

FIG. 16. Annual and seasonal spatial distribution of the vertical wind shear trends $\left(\mathrm{m} \mathrm{s}^{-1} \mathrm{decade}^{-1}\right)$ across Australia and surroundings for $1948-2016$. A small black x represents a $2.5^{\circ} \times 2.5^{\circ}$ grid cell with a significant trend at $p<0.05$.

sites the occurrence of wind gusts declined at a lower rate when compared to mid- and low-elevation sites. The seasonal cycle is also discerned among regions.

4) Changes in oceanic-atmospheric circulation partly controls the observed DPWG trends. The southern annual mode, Indian Ocean dipole, and Madden-Julian oscillation indices displayed significant $(p<0.05)$ correlations with the
DPWG variability. El Niño-Southern Oscillation has only limited correlation with DPWG trends.

5) The five interrelated physical factors examined also partly explain the observed trends and multidecadal variability of DPWG. However, attribution of changes in wind gusts deserves further focused and comprehensive analyses to reveal the principal driver(s) controlling their changes. 
ETC Frequency
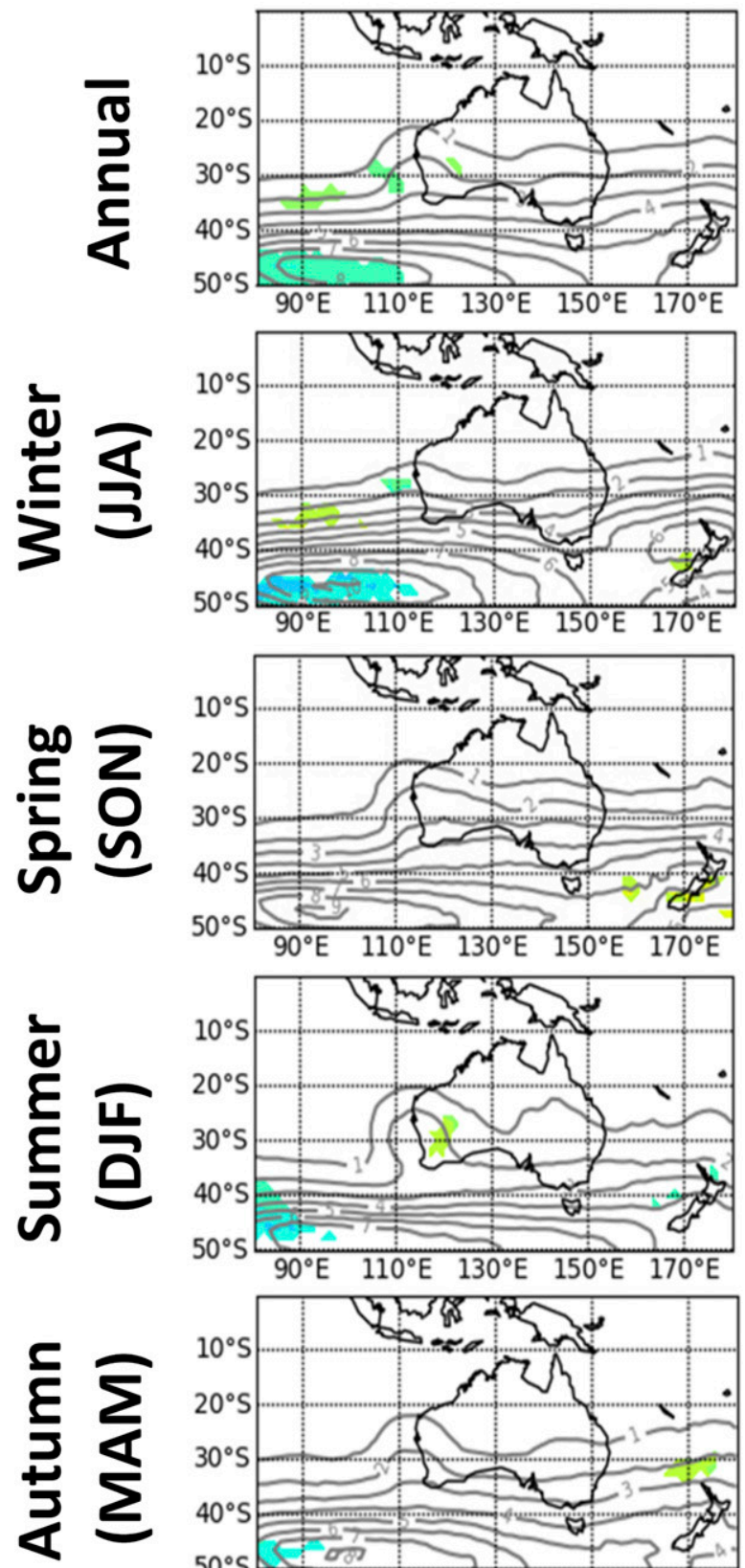

ETC Intensity
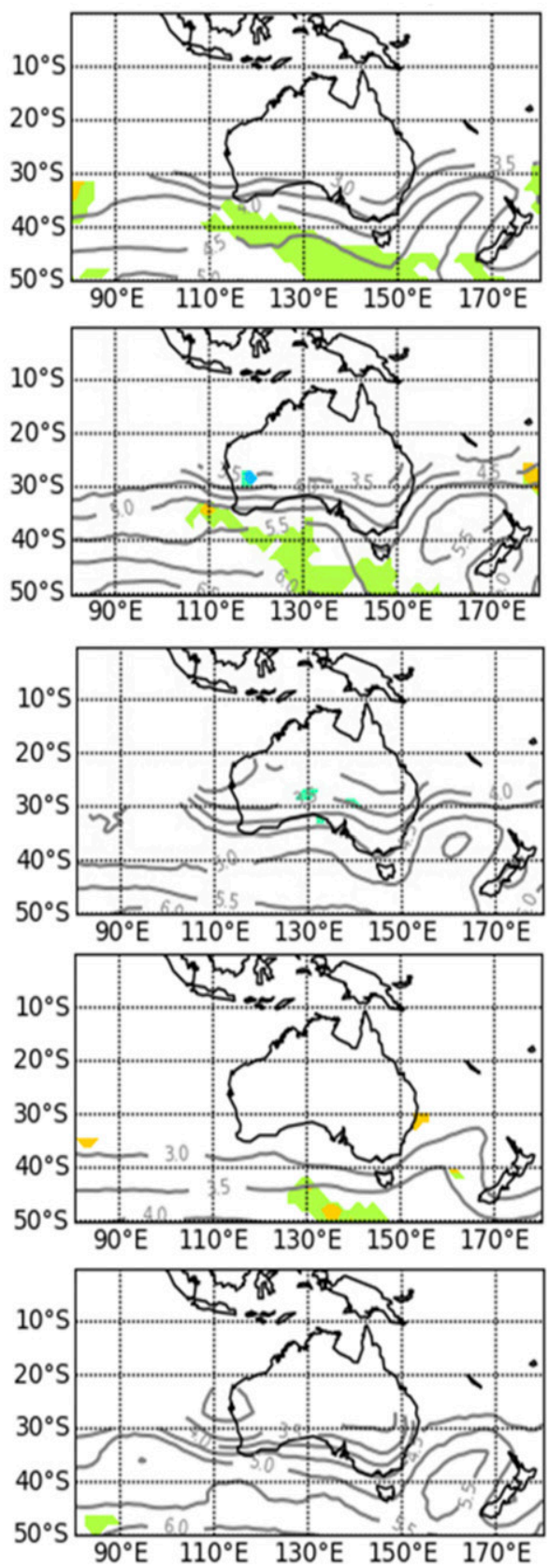

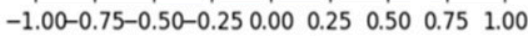
CVU/decade

FIG. 17. Long-term trend of annual-mean or seasonal-mean ETC frequency (number month ${ }^{-1}$ decade $^{-1}$ ) and intensity (CVU decade ${ }^{-1}$ ) around Australia for 1975-2016. The JRA-55 data are used. Due to the sampling issue, ETC intensity is shown only when ETC frequency is greater than $1.0 \mathrm{month}^{-1}$. Only statistically significant trends $(p<0.05)$ are shaded, with contours showing the climatology. 
Acknowledgments. C.A.M. was supported by Ramon y Cajal fellowship (RYC-2017-22830) and Grants VR-2017-03780 and RTI2018-095749-A-I00 (MCIU/AEI/FEDER, UE). G.F.Z. was supported by the Second Tibetan Plateau Scientific Expedition and Research Program (2019QZKK0606) and National Natural Science Foundation of China (Grant 41621061). S.W.S. was partly supported by the National Research Foundation of Korea (NRF) grant funded by the South Korean government (MSIT) (NRF2018R1A5A1024958). We acknowledge the two anonymous reviewers for their detailed and helpful comments to the original manuscript.

\section{REFERENCES}

Achberger, C., D. Chen, and H. Alexandersson, 2006: The surface winds of Sweden during 1999-2000. Int. J. Climatol., 26, 159178, https://doi.org/10.1002/joc.1254.

Aguilar, E., I. Auer, M. Brunet, T. C. Peterson, and J. Wieringa, 2003: Guidelines on climate metadata and homogenization. World Meteorological Organization Tech. Rep. WMO/TD-1186, 52 pp. https://library.wmo.int/index.php?lvl=notice_display\&id= 11635\#.Xt91kEUzaUk.

Alexander, L. V., X. L. Wang, H. Wan, and B. Trewin, 2011: Significant decline in storminess over southeast Australia since the late 19th century. Aust. Meteor. Oceanogr. J., 61, 23-30, https://doi.org/10.22499/2.6101.002.

Alexandersson, H., 1986: A homogeneity test applied to precipitation data. Int. J. Climatol., 6, 661-675, https://doi.org/ 10.1002/joc.3370060607.

Allen, J. T., and E. R. Allen, 2016: A review of severe thunderstorms in Australia. Atmos. Res., 178-179, 347-366, https:// doi.org/10.1016/j.atmosres.2016.03.011.

Azorin-Molina, C., and Coauthors, 2014: Homogenization and assessment of observed near-surface wind speed trends over Spain and Portugal, 1961-2011. J. Climate, 27, 3692-3712, https://doi.org/10.1175/JCLI-D-13-00652.1.

, J. A. Guijarro, T. R. McVicar, S. M. Vicente-Serrano, D. Chen, S. Jerez, and F. Espírito-Santo, 2016: Trends of daily peak wind gusts in Spain and Portugal, 1961-2014. J. Geophys. Res. Atmos., 121, 1059-1078, https://doi.org/10.1002/2015JD024485.

— , J. Asin, T. R. McVicar, L. Minola, J. I. Lopez-Moreno, S. M. Vicente-Serrano, and D. Chen, 2018a: Evaluating anemometer drift: A statistical approach to correct biases in wind speed measurement. Atmos. Res., 203, 175-188, https://doi.org/10.1016/ j.atmosres.2017.12.010.

- M. Menendez, T. R. McVicar, A. Acevedo, S. M. VicenteSerrano, E. Cuevas, L. Minola, and D. Chen, 2018b: Wind speed variability over the Canary Islands, 1948-2014: Focusing on trend differences at the land-ocean interface and belowabove the trade-wind inversion layer. Climate Dyn., 50, 40614081, https://doi.org/10.1007/s00382-017-3861-0.

— J. A. Guijarro, T. R. McVicar, B. C. Trewin, A. J. Frost, and D. Chen, 2019: An approach to homogenize daily peak wind gusts: An application to the Australian series. Int. J. Climatol., 39, 2260-2277, https://doi.org/10.1002/joc.5949.

Bellprat, O., V. Guemas, F. Doblas-Reyes, and M. G. Donat, 2019: Towards reliable extreme weather and climate event attribution. Nat. Commun., 10, 1732, https://doi.org/10.1038/s41467-019-09729-2.

Borchers Arriagada, N., A. J. Palmer, D. M. J. S. Bowman, G. G. Morgan, B. B. Jalaludin, and F. H. Johnston, 2020: Unprecedented smoke-related health burden associated with the 2019-20 bushfires in eastern Australia. Med. J. Aust., 213, 282-283, https://doi.org/ 10.5694/mja2.50545.
Brázdil, R., J. Hostýnek, L. Rezníčková, P. Zahradníček, R. Tolasz, P. Dobrovolný, and P. Štěpánek, 2017: The variability of maximum wind gusts in the Czech Republic between 1961 and 2014. Int. J. Climatol., 37, 1961-1978, https://doi.org/10.1002/joc.4827.

Brown, A., and A. Dowdy, 2019: Extreme wind gusts and thunderstorms in South Australia analysed from 1979-2017. Bureau of Meteorology Bureau Research Rep. 034, 63 pp.

Cechet, R. P., and L. A. Sanabria, 2012: Statistical comparison of coincident wind gust measurements from Dines and cup anemometers. 15th Australasian Wind Engineering Society Workshop, Sydney, NSW, Australia, Australasian Wind Engineering Society, 97-100.

Chand, S. S., and Coauthors, 2019: Review of tropical cyclones in the Australian region: Climatology, variability, predictability, and trends. Wiley Interdiscip. Rev.: Climate Change, 10, e602, https://doi.org/10.1002/wcc.602.

Chen, D., and Coauthors, 2020: Summary of a workshop on extreme weather events in a warming world organized by the Royal Swedish Academy of Sciences. Tellus, 72B, 1-13, https://doi.org/10.1080/16000889.2020.1794236.

Clarke, S. J., S. L. Gray, and N. M. Roberts, 2019: Downstream influence of mesoscale convective systems. Part 2: Influence on ensemble forecast skill and spread. Quart. J. Roy. Meteor. Soc., 145, 2953-2972, https://doi.org/10.1002/qj.3613.

Conrad, V., and L. W. Pollak, 1950: Methods in Climatology. Harvard University Press, 459 pp.

CSIRO and BoM, 2015: Climate change in Australia: Projections for Australia's NRM Regions. CSIRO and BoM Tech. Rep., 222 pp., https://www.climatechangeinaustralia.gov.au/media/ccia/2.1.6/cms_ page_media/168/CCIA_2015_NRM_TechnicalReport_WEB.pdf.

Dadaser-Celik, F., and E. Cengiz, 2014: Wind speed trends over Turkey from 1975 to 2006. Int. J. Climatol., 34, 1913-1927, https://doi.org/10.1002/joc.3810.

Dowdy, A. J., 2016: Seasonal forecasting of lightning and thunderstorm activity in tropical and temperate regions of the world. Sci. Rep., 6, 20874, https://doi.org/10.1038/srep20874. , 2020: Climatology of thunderstorms, convective rainfall and dry lightning environments in Australia. Climate Dyn., 54, 3041-3052, https://doi.org/10.1007/s00382-020-05167-9.

_ and J. L. Catto, 2017: Extreme weather caused by concurrent cyclone, front and thunderstorm occurrences. Sci. Rep., 7, 40359, https://doi.org/10.1038/srep40359.

Evans, J. P., M. Kay, A. Prasad, and A. Pitman, 2018: The resilience of Australian wind energy to climate change. Environ. Res. Lett., 13, 024014, https://doi.org/10.1088/1748-9326/aaa632.

Gillett, N. P., T. D. Kell, and P. D. Jones, 2006: Regional climate impacts of the southern annular mode. Geophys. Res. Lett., 33, L23704, https://doi.org/10.1029/2006GL027721.

Grise, K. M., S. Son, and J. R. Gyakum, 2013: Intraseasonal and interannual variability in North American storm tracks and its relationship to equatorial Pacific variability. Mon. Wea. Rev., 141, 3610-3625, https://doi.org/10.1175/MWR-D-12-00322.1.

Guijarro, J. A., 2018: Homogenization of climate series with Climatol. 22 pp., http://www.climatol.eu/homog_climatol-en.pdf.

Guo, H., M. Xu, and Q. Hu, 2011: Changes in near-surface wind speed in China: 1969-2005. Int. J. Climatol., 31, 349-358, https://doi.org/10.1002/joc.2091.

Gutiérrez, A., C. Porrini, and R. G. Fovell, 2020: Combination of wind gust models in convective events. J. Wind Eng. Ind. Aerodyn., 199, 104118, https://doi.org/10.1016/j.jweia.2020.104118.

Hendon, H. H., D. W. J. Thompson, and M. C. Wheeler, 2007: Australian rainfall and surface temperature variations associated with the Southern Hemisphere annular mode. $J$. Climate, 20, 2452-2467, https://doi.org/10.1175/JCLI4134.1. 
Herring, S. C., A. Hoell, M. P. Hoerling, J. P. Kossin, C. J. Schreck III, and P. A. Stott, 2016: Explaining extreme events of 2015 from a climate perspective. Bull. Amer. Meteor. Soc., 97 (12), S1-S145, https://doi.org/10.1175/BAMS-ExplainingExtremeEvents2015.1.

Holmes, J., and J. D. Ginger, 2012: The gust wind speed duration in AS/NZS 1170.2. Aust. J. Struct. Eng., 13, 207-218, https:// doi.org/10.7158/S12-017.2012.13.3.

Hoskins, B. J., and K. I. Hodges, 2002: New perspectives on the Northern Hemisphere winter storm tracks. J. Atmos. Sci., 59, 1041-1061, https://doi.org/10.1175/1520-0469(2002)059<1041: NPOTNH $>2.0 . \mathrm{CO} ; 2$.

IPCC, 2013: Climate Change 2013: The Physical Science Basis. Cambridge University Press, 1535 pp., https://doi.org/10.1017/ CBO9781107415324.

Jakob, D., 2010: Challenges in developing a high-quality surface wind-speed data-set for Australia. Aust. Meteor. Oceanogr. J., 60, 227-236, https://doi.org/10.22499/2.6004.001.

Jiménez, P. A., and J. Dudhia, 2012: Improving the representation of resolved and unresolved topographic effects on surface wind in the WRF Model. J. Appl. Meteor. Climatol., 51, 300316, https://doi.org/10.1175/JAMC-D-11-084.1.

Jones, D. A., and I. Simmonds, 1993: A climatology of Southern Hemisphere extratropical cyclones. Climate Dyn., 9, 131-145, https://doi.org/10.1007/BF00209750.

Kalnay, E., and Coauthors, 1996: The NCEP/NCAR 40-Year Reanalysis Project. Bull. Amer. Meteor. Soc., 77, 437-471, https:// doi.org/10.1175/1520-0477(1996)077<0437:TNYRP>2.0.CO;2.

Kendall, M. G., and J. D. Gibbons, 1990: Rank Correlation Methods. Oxford University Press, 272 pp.

Kobayashi, S., and Coauthors, 2015: The JRA-55 reanalysis: General specifications and basic characteristics. J. Meteor. Soc. Japan, 93, 5-48, https://doi.org/10.2151/jmsj.2015-001.

Laapas, M., and A. Venäläinen, 2017: Homogenization and trend analysis of monthly mean and maximum wind speed time series in Finland, 1959-2015. Int. J. Climatol., 37, 4803-4813, https://doi.org/10.1002/joc.5124.

Lee, J., S.-W. Son, H.-O. Cho, J. Kim, D.-H. Cha, J. R. Gyakum, and D. Chen, 2020: Extratropical cyclones over East Asia: Climatology, seasonal cycle, and long-term trend. Climate Dyn., 54, 1131-1144, https://doi.org/10.1007/s00382-019-05048-w.

Li, Y., Y. Chen, Z. Li, and G. Fang, 2018: Recent recovery of surface wind speed in northwest China. Int. J. Climatol., 38, 4445-4458, https://doi.org/10.1002/joc.5679.

Lin, C., K. Yang, J. Qin, and R. Fu, 2013: Observed coherent trends of surface and upper-air wind speed over China since 1960. J. Climate, 26, 2891-2903, https://doi.org/10.1175/JCLI-D-1200093.1.

Livezey, R. E., and W. Y. Chen, 1983: Statistical field significance and its determination by Monte Carlo techniques. Mon. Wea. Rev., 111, 46-59, https://doi.org/10.1175/1520-0493(1983)111<0046: SFSAID $>2.0 . \mathrm{CO} ; 2$.

McVicar, T. R., T. G. Van Niel, L. T. Li, M. L. Roderick, D. P. Rayner, L. Ricciardulli, and R. J. Donohue, 2008: Wind speed climatology and trends for Australia, 1975-2006: Capturing the stilling phenomenon and comparison with near-surface reanalysis output. Geophys. Res. Lett., 35, L20403, https:// doi.org/10.1029/2008GL035627.

, M. L. Roderick, L. T. Li, X. G. Mo, N. E. Zimmermann, and D. R. Schmatz, 2010: Observational evidence from two mountainous regions that near-surface wind speeds are declining more rapidly at higher elevations than lower elevations: 1960-2006. Geophys. Res. Lett., 37, L06402, https:// doi.org/10.1029/2009GL042255.
— in observed terrestrial near-surface wind speeds: Implications for evaporation. J. Hydrol., 416-417, 182-205, https://doi.org/ 10.1016/j.jhydrol.2011.10.024.

_, M. L. Roderick, R. J. Donohue, and T. G. Van Niel, 2012b: Less bluster ahead? Ecohydrological implications of global trends of terrestrial near-surface wind speeds. Ecohydrology, 5, 381-388, https://doi.org/10.1002/eco.1298.

Minola, L., C. Azorin-Molina, and D. Chen, 2016: Homogenization and assessment of observed near-surface wind speed trends across Sweden, 1956-2013. J. Climate, 29, 7397-7415, https:// doi.org/10.1175/JCLI-D-15-0636.1.

- F. Zhang, C. Azorin-Molina, A. A. Safaei Pirooz, R. G. J. Flay, H. Hersbach, and D. Chen, 2020: Near-surface mean and gust wind speeds in ERA5 across Sweden: Towards an improved gust parametrization. Climate Dyn., 55, 887-907, https://doi.org/10.1007/s00382-020-05302-6.

Nikulin, G., E. Kjellström, U. Hansson, G. Strandberg, and A. Ullerstig, 2010: Evaluation and future projections of temperature, precipitation and wind extremes over Europe in an ensemble of regional climate simulations. Tellus, $\mathbf{6 3 A}, 41-55$, https://doi.org/10.1111/j.1600-0870.2010.00466.x.

Pepler, A., 2020: Record lack of cyclones in southern Australia during 2019. Geophys. Res. Lett., 47, e2020GL088488, https:// doi.org/10.1029/2020GL088488.

Prein, A. F., and Coauthors, 2015: A review on regional convection-permitting climate modeling: Demonstrations, prospects, and challenges. Rev. Geophys., 53, 323-361, https:// doi.org/10.1002/2014RG000475.

Roderick, M. L., L. D. Rotstayn, G. D. Farquhar, and M. T. Hobbins, 2007: On the attribution of changing pan evaporation. Geophys. Res. Lett., 34, L17403, https://doi.org/10.1029/2007GL031166.

Rotach, M. W., A. Gohm, M. N. Lang, D. Leukauf, I. Stiperski, and J.S. Wagner, 2015: On the vertical exchange of heat, mass, and momentum over complex, mountainous terrain. Front. Earth Sci., 3, 76, https://doi.org/10.3389/feart.2015.00076.

Shi, P., G. Zhang, D. Chen, C. Azorin-Molina, and J. A. Guijarro, 2019: Variability of winter haze over the Beijing-TianjinHebei region tied to wind speed in the lower troposphere and particulate sources. Atmos. Res., 215,1-11, https://doi.org/ 10.1016/j.atmosres.2018.08.013.

Timbal, B., R. Kounkou, and G. A. Mills, 2010: Changes in the risk of cool-season tornadoes over southern Australia due to model projections of anthropogenic warming. J. Climate, $\mathbf{2 3}$, 2440-2449, https://doi.org/10.1175/2009JCLI3456.1.

Tobin, I., P. Berrisford, R. J. H. Dunn, R. Vautard, and T. R. McVicar, 2014: Land surface wind speed [in "State of the Climate in 2013"']. Bull. Amer. Meteor. Soc., 95 (7), S28-S29, https://doi.org/10.1175/2014BAMSStateoftheClimate.1.

Troccoli, A., K. Muller, P. Coppin, R. Davy, C. Russell, and A. L. Hirsch, 2012: Long-term wind speed trends over Australia. J. Climate, 25, 170-183, https://doi.org/10.1175/ 2011JCLI4198.1.

Vautard, R., and Coauthors, 2019: Human influence on European winter wind storms such as those of January 2018. Earth Syst. Dyn., 10, 271-286, https://doi.org/10.5194/esd-10-271-2019.

Venema, V. K. C., and Coauthors, 2012: Benchmarking homogenization algorithms for monthly data. Climate Past, 8, 89-115, https://doi.org/10.5194/cp-8-89-2012.

von Storch, H., 1995: Misuses of statistical analysis in climate research. Analysis of Climate Variability: Applications of Statistical Techniques, H. von Storch and A. Navarra, Eds., Springer, 11-26. 
Vose, R. S., and Coauthors, 2014: Monitoring and understanding changes in extremes: Extratropical storms, winds, and waves. Bull. Amer. Meteor. Soc., 95, 377-386, https://doi.org/10.1175/ BAMS-D-12-00162.1.

Walsh, K., and Coauthors, 2016: Natural hazards in Australia: Storms, wind and hail. Climatic Change, 139, 55-67, https:// doi.org/10.1007/s10584-016-1737-7.

Walz, M. A., M. G. Donat, and G. C. Leckebusch, 2018: Large-scale drivers and seasonal predictability of extreme wind speeds over the North Atlantic and Europe. J. Geophys. Res. Atmos., 123, 11 518-11 535, https://doi.org/10.1029/2017JD027958.

Wan, H., L. W. Xiaolan, and V. R. Swail, 2010: Homogenization and trend analysis of Canadian near-surface wind speeds. J. Climate, 23, 1209-1225, https://doi.org/10.1175/2009JCLI3200.1.

Wang, C. H., X. M. Wang, and Y. B. Khoo, 2013: Extreme wind gust hazard in Australia and its sensitivity to climate change. Nat. Hazards, 67, 549-567, https://doi.org/10.1007/s11069-013-0582-5.

Wilks, D. S., 2006: On "field significance" and the false discovery rate. J. Appl. Meteor. Climatol., 45, 1181-1189, https://doi.org/ 10.1175/JAM2404.1.
WMO, 1987: The measurement of gustiness at routine wind stations-A review. IOM Rep. 31, 52 pp., https://library.wmo.int/ index.php?lvl=notice_display\&id=15514\#.X8D3B2j7SUk.

Young, I. R., and A. Ribal, 2019: Multiplatform evaluation of global trends in wind speed and wave height. Science, 364, 548552, https://doi.org/10.1126/science.aav9527.

Zeng, Z., and Coauthors, 2018: Global terrestrial stilling: Does Earth's greening play a role? Environ. Res. Lett., 13, 124013, https://doi.org/10.1088/1748-9326/aaea84.

— , and Coauthors, 2019: A reversal in global terrestrial stilling and its implications for wind energy production. Nat. Climate Change, 9, 979-985, https://doi.org/10.1038/s41558-019-0622-6.

Zhang, G., and Coauthors, 2020: Variability of daily maximum wind speed across China, 1975-2016: An examination of likely causes. J. Climate, 33, 2793-2816, https://doi.org/10.1175/ JCLI-D-19-0603.1.

Zhang, R., Q. Li, and R. Zhang, 2014: Meteorological conditions for the persistent severe fog and haze event over eastern China in January 2013. Sci. China Earth Sci., 57, 26-35, https:// doi.org/10.1007/s11430-013-4774-3. 